\title{
Reducing the transmission of HIV and sexually transmitted infections in a mining community: Findings from the Carletonville Mothusimpilo intervention project: 1998 to 2001
}

\author{
Lewis Ndhlovu \\ Population Council \\ Catherine Searle \\ Johannes van Dam \\ Population Council \\ Yodwa Mzaidume \\ Bareng Rasego
}

See next page for additional authors

Follow this and additional works at: https://knowledgecommons.popcouncil.org/departments_sbsr-hiv

Part of the Demography, Population, and Ecology Commons, Gender and Sexuality Commons, Health Policy Commons, Immune System Diseases Commons, International Public Health Commons, Medicine and Health Commons, Public Health Education and Promotion Commons, and the Virus Diseases Commons

How does access to this work benefit you? Let us know!

\section{Recommended Citation}

Ndhlovu, Lewis, Catherine Searle, Johannes van Dam, Yodwa Mzaidume, Bareng Rasego, and Solly Moema. 2005. "Reducing the transmission of HIV and sexually transmitted infections in a mining community: Findings from the Carletonville Mothusimpilo intervention project: 1998 to 2001," Horizons Final Report. Washington, DC: Population Council. 


\section{Authors}

Lewis Ndhlovu, Catherine Searle, Johannes van Dam, Yodwa Mzaidume, Bareng Rasego, and Solly Moema 


\section{Hprizons}

Reducing the Transmission of HIV and Sexually Transmitted Infections in a Mining Community

Findings from the Carletonville Mothusimpilo Intervention Project: 1998 to 2001

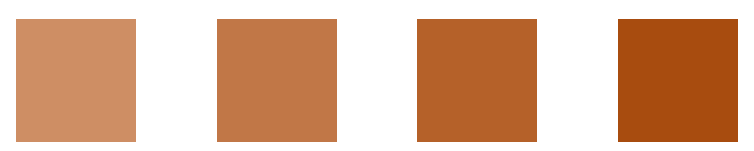

Horizons Program

Mothusimpilo Intervention Project 


\title{
Reducing the Transmission of HIV and Sexually Transmitted I nfections in a Mining Community
}

\section{Findings from the Carletonville Mothusimpilo Intervention Project; 1998 to 2001}

\author{
Horizons Program \\ Lewis Ndhlovu \\ Catherine Searle \\ Johannes van Dam
}
Mothusimpilo I ntervention Project
Yodwa Mzaidume
Bareng Rasego
Solly Moema




\section{Acknowledgments}

This study was supported by the U.S. Agency for International Development (USAID) through the Population Council's Horizons Program. A number of other donors and institutions also contributed during the life of the project, including the British Government's Department for International Development, the Gauteng Department of Health, the Center for Scientific and Industrial Research, and Family Health International through the South African Institute for Medical Research. Staff members from the London School of Economics and the Institut National de la Santé et de la Recherche Médicale must also be acknowledged for providing technical assistance to the project.

In addition, the stakeholders in the project including representatives from the local, provincial, and national levels of government; representatives from the Carletonville AIDS Action Committee; mining companies; and trade unions, have played a vital role in increasing the community acceptability of the project and in contributing to its sustainability.

The contributions of Progressus cc., the organization contracted to conduct the surveys, the data collectors, and the respondents who participated in the study, are also acknowledged.

This research was supported by the Horizons Program, which is implemented by the Population Council in collaboration with the International Center for Research on Women, International HIV/AIDS Alliance, PATH, Tulane University, Family Health International, and Johns Hopkins University. Horizons is funded by the President's Emergency Plan for AIDS Relief through the U.S. Agency for International Development, under the terms of HRN-A-00-97-00012-00. The opinions expressed herein are those of the authors and do not necessarily reflect the views of the U.S. Agency for International Development.

\section{(P) Population Council}

The Population Council is an international, nonprofit, nongovernmental institution that seeks to improve the well-being and reproductive health of current and future generations around the world and to help achieve a humane, equitable and sustainable balance between people and resources. The Council conducts biomedical, social science, and public health research and helps build research capacities in developing countries. Established in 1952, the Council is governed by an international board of trustees. Its New York headquarters supports a global network of regional and country offices.

Copyright (C) 2005 The Population Council Inc.

This document may be reproduced in whole or in part without permission of the Population Council provided full source citation is given and the reproduction is not for commercial purposes.

Suggested citation: Ndhlovu, Lewis, Catherine Searle, Johannes van Dam, Yodwa Mzaidume, Bareng Rasego, Solly Moema. 2005. "Reducing the transmission of HIV and sexually transmitted infections in a mining community: Findings from the Carletonville Mothusimpilo intervention project: 1998 to 2001,” Horizons Final Report. Washington, DC: Population Council. 


\section{Table of Contents}

\section{Abbreviations}

Executive Summary

Introduction

$\begin{array}{ll}\text { Description of the intervention } & 7\end{array}$

Implementation of the intervention: Challenges and accomplishments 8

$\begin{array}{ll}\text { Methodology } & 11\end{array}$

Community-based surveys 11

$\begin{array}{ll}\text { Qualitative assessment of STI services } & 13\end{array}$

$\begin{array}{ll}\text { The role of social organizations } & 14\end{array}$

$\begin{array}{ll}\text { Sexual networking among sex workers } & 15\end{array}$

$\begin{array}{lr}\text { Findings } & 16\end{array}$

$\begin{array}{lr}\text { Description of the Carletonville study population } & 16\end{array}$

HIV/AIDS knowledge 17

$\begin{array}{ll}\text { Sexual behavior } & 18\end{array}$

Sexually transmitted infections and HIV $\quad 21$

Health-seeking behavior and utilization of STI services $\quad 24$

Quality of STI services in Carletonville $\quad 24$

$\begin{array}{ll}\text { Sexual networks in Carletonville } & 27\end{array}$

The role of social organizations 30

Community mobilization and project management 32

Discussion 34

$\begin{array}{ll}\text { Recommendations } & 37\end{array}$

References $\quad 39$ 


\section{Abbreviations}

$\begin{array}{ll}\text { CSIR } & \text { Center for Scientific and Industrial Research } \\ \text { CME } & \text { Continuing Medical Education } \\ \text { DHS } & \text { Demographic and Health Surveys } \\ \text { DOH } & \text { Department of Health } \\ \text { FGD } & \text { Focus Group Discussions } \\ \text { GP } & \text { General Practitioner } \\ \text { HSRC } & \text { Human Sciences Research Council } \\ \text { HSV-2 } & \text { Herpes Simplex Virus Type 2 } \\ \text { IDI } & \text { In-depth Interviews } \\ \text { IEC } & \text { Information, Education, and Communication } \\ \text { LSE } & \text { London School of Economics } \\ \text { MIP } & \text { Mothusimpilo Intervention Project } \\ \text { NMCF } & \text { Nelson Mandela Children's Fund } \\ \text { PLHA } & \text { People Living with HIV/AIDS } \\ \text { PPT } & \text { Periodic Presumptive Treatment } \\ \text { STI } & \text { Sexually Transmitted Infection } \\ \text { SWs } & \text { Sex Workers } \\ \text { SAIMR } & \text { South African Institute for Medical Research } \\ \text { TB } & \text { Tuberculosis } \\ \text { USAID } & \text { United States Agency for International Development } \\ \text { US } & \text { United States }\end{array}$




\section{Executive Summary}

The Horizons Program, in collaboration with the Center for Scientific and Industrial Research (CSIR), the South African Institute for Medical Research (SAIMR), and the London School of Economics (LSE), conducted an intervention study in the mining town of Carletonville, South Africa to study the social determinants of the HIV epidemic, and to assess the impact of a targeted program of HIV and STI prevention and service delivery. In 1998 the Mothusimpilo (“working together for health”) Intervention Project (MIP) was launched by the study partners to reduce the transmission of HIV and other sexually transmitted infections (STIs) in Carletonville. At the time, the population of Carletonville and the neighboring township of Khutsong was approximately 130,000 people. In addition, more than 70,000 men working in 12 gold mining shafts near Carletonville were living in single sex hostels (Campbell and Mzaidume 2002). Poverty and unemployment rates were high in Carletonville and sex work was well established.

The objectives of the project were to reduce the community prevalence of STIs and the incidence of HIV infection, and to sustain these reductions through enhanced information, education, and communication (IEC) activities and effective STI services. The interventions focused primarily on two populations perceived to be at high risk of HIV and other STIs: female sex workers (SWs) and male mine workers. We hypothesized that focusing interventions on these two groups would reduce the transmission of HIV and have an impact on HIV incidence in the wider community.

The hypothesis of the intervention stipulated that focusing on these two population groups would in turn reduce transmission of STIs and HIV to men and women in the community at large. The intervention had three components: peer education on HIV/STI knowledge and prevention, condom promotion and distribution by peer educators, and improved management of STIs, including periodic presumptive treatment (PPT) of SWs.

\section{I mplementation of the intervention components}

The intervention implemented three key components. The first component was behavior change communication through peer education. A number of SWs were recruited and trained in community work, hygiene, HIV/AIDS, and signs and symptoms of STIs. They provided information to other SWs, and to a limited extent, the community at large. A similar program was designed to target mine workers who were perceived to be the primary clients of SWs. The peer education program among SWs was very strong and well-supervised. However, the implementation of the peer education program with the mine workers experienced delays and unfortunately, its implementation and coordination with other MIP activities was weak.

The second component of the intervention was the promotion and distribution of free condoms to SWs and mine workers. The third component sought to strengthen STI services at private and public health facilities in Carletonville through the training of service providers in STI case management. In addition, beginning in 2000 SWs were able to enroll in a presumptive treatment program for gonorrhea and chlamydia. Those SWs who enrolled were given one gram of azithromycin per month to presumptively treat both STIs. 


\section{Hgrizons}

\section{Methods}

This report is based on qualitative and quantitative findings from different data collection activities including:

- A pre-intervention survey (1998) of a random, representative sample of 489 men and 710 women from the Khutsong community, 121 SWs from established sex worker venues or "hotspots," and 898 mine workers.

- A post-intervention survey (2001) of 532 men and 878 women, 101 SWs, and 998 mine workers from the same communities as those sampled for the pre-intervention survey.

- Focus group discussions (FGDs) and interviews with SWs to learn more about sexual behavior and networks.

- FGDs and interviews with members of social organizations to understand the role they play in HIV prevention and sexual risk.

- Two assessments of the quality of care of STI services provided by the public, private, and mining sectors and traditional healers (1999 and 2000).

The two surveys allowed for comparison between baseline (pre-intervention) data collected in 1998 and endline (post-intervention) data collected in 2001. The sample sizes for each crosssectional study were calculated to detect a 30 percent decrease in HIV incidence from baseline to endline, based on the total population and estimated HIV incidence rates.

Survey respondents were interviewed face-to-face to elicit information on demographics, sexual behavior and partnerships, sexual health, participation in social organizations, and HIV/AIDS knowledge. Matched urine and blood samples were also taken to test for HIV, syphilis, gonorrhea, chlamydia, and HSV-2 in 2001. HIV incidence was to be calculated for each survey sample on the basis of the results of a detuned ELISA (Schwarcz 1999). Ultimately this test was not used because of questions about its usefulness in this context to measure recent seroconversions. Therefore, the findings do not include HIV incidence.

The survey data were complemented by other data on the quality of STI services in Carletonville, the protective and risk factors of social organizations, and sexual behavior and partnerships among SWs. This report synthesizes findings from the various data sources in order to present an integrated picture of the intervention, its impact, and lessons learned.

\section{Key findings}

\section{Knowledge of HIV transmission}

Knowledge of HIV transmission was high at baseline and increased further by 2001. Although fewer respondents answered questions correctly when asked about erroneous modes of HIV transmission (e.g., whether mosquitos transmit HIV) at baseline compared to other knowledge questions, there was improvement in these items among all groups by 2001. Widespread HIV/AIDS messages from multiple sources and the fragmented peer education program among mine workers made it impossible to attribute increases in HIV transmission knowledge solely to the MIP information, education, and communication activities. 


\section{HIV prevalence}

Between 1998 and 2001, with the exception of men in the community, all groups experienced an increase in HIV prevalence. HIV prevalence among mine workers increased significantly from 29 percent to 36 percent $(\mathrm{p}<.001)$. It also increased among SWs from 69 percent to 78 percent. Prevalence levels significantly increased among women in the community, rising from 37 percent to 45 percent $(\mathrm{p}<.001)$. Men in the community experienced a slight decrease from 22 percent to 20 percent.

\section{STI prevalence}

Despite administration of PPT for bacterial STIs among SWs over a period of 18 months and training of providers for improved STI services, the prevalence of STIs among SWs, mine workers, and men in the community remained constant or slightly increased. Significant increases were noted among women in the community between 1998 and 2001. In this group, the prevalence of syphilis increased from 10 to 13 percent $(p=0.05)$, chlamydia from 8 to 12 percent $(p=0.01)$, and gonorrhea from 7 to 11 percent $(p=0.01)$.

\section{Number of sexual partners}

From 1998 to 2001 the percentage of mine workers reporting one or more casual partners in the 12 months prior to each survey decreased significantly from 53 to 43 percent $(\mathrm{p}<.001)$. The proportion of men in the community reporting that they had one or more casual partner in the previous 12 months increased from 37 to 45 percent. In 2001, 41 percent of women in the community reported having casual partners, which was significantly higher than the figure of 24 percent reported in $1998(\mathrm{p}<.001)$.

\section{Condom use}

Reported consistent condom use with casual partners increased significantly from 1998 to 2001 among mine workers (19 to 24 percent, $\mathrm{p}=0.02$ ) and men in the community (28 to 37 percent, $\mathrm{p}=0.04$ ). Among women in the community it increased only slightly, from 22 percent to 25 percent. The proportion of SWs who reported using a condom with their last casual partner did not increase over the survey period. Very few mine workers reported always using a condom with their regular partner (6 percent in 1998 and 4 percent in 2001). The percentage of SWs using condoms consistently with regular partners decreased from 26 percent to 12 percent. Consistent condom use with regular partners among men (9 percent in 1998 and 6 percent in 2001) and women (6 percent in 1998 and 5 percent in 2001) in the community remained low.

\section{Quality of STI services}

There remains room for improvement in the quality of treatment of STIs in both the public and private sector. Further training is needed in the treatment of warts, herpes, buboes, and genital ulcers. Rational drug use and over-prescription in the public sector also need to be addressed. Both mine workers and men in the community reported frequently seeking care for STIs from traditional healers due to the quality of care that they provide. Traditional healers were systematically included in the STI training provided by the project. 


\section{Hgrizons}

\section{Role of sexual networks}

Analysis revealed that sexual networks in Carletonville were more complex than originally believed, linking mine workers, SWs, men, and women in the community. Mine workers had casual relationships with SWs as well as other women in the community outside of the "hotspots." Women living in these other areas did not self-identify as SWs, but many operated as such. This group of women was overlooked when designing the intervention.

\section{Role of social organizations in HIV risk}

Depending on the type of organization, membership was found to be associated with either a greater or lesser level of HIV risk. For example, men in the community who were members of a sports group were found to be at a reduced risk for HIV infection. Similarly, women in the community and mine workers who were active church members were less likely to be HIV positive. Membership in stokvels (informal rotating credit schemes), political parties, and burial societies was associated with higher risk behavior, in particular having an increased number of sexual partners. Qualitative discussions found that churches and youth and sports clubs promoted good moral behavior, while stokvels, political parties, and burial societies were linked with wild parties where alcohol consumption and risky sexual behavior were the norm. However, it is not clear whether these findings are a result of self-selection of individuals into particular groups or a result of group norms and values in those organizations influencing the behavior of members.

\section{Project management and community participation}

Initial funding of the project ended in 2001, but the MIP has persevered as a community project. Local stakeholders continue to be key players, as are the mine workers. This privatepublic sector partnership has provided the project with the financial support and management skills needed to sustain MIP.

\section{Conclusions}

The MIP did not reduce STI prevalence or HIV prevalence. Given the high HIV prevalence rates in 1998, especially among SWs and women in the community, the challenge was great. Further, interventions among mine workers were delayed and not implemented with sufficient intensity. For both SWs and mine workers, 100 percent condom use was not achieved. This situation was aggravated by the complex sexual networks between mine workers, SWs, and the community, which may have limited the impact of PPT among SWs and behavioral change interventions targeting both SWs and mine workers. Despite interventions to address the quality of STI treatment, respondents in Carletonville did not always receive appropriate treatment for a variety of STI conditions.

Changing sexual behavior is far more complex than educating individuals about HIV. More comprehensive peer education was implemented for SWs, but it failed to achieve universal condom use among SWs. The absence of a sustained peer education program for men in the community and in the mines meant that men were receiving limited information and support regarding behavior change. It is possible that the condom distribution activities among mine 
workers could have contributed to the increase in mine workers' reported use of condoms with their last casual partner.

\section{Recommendations}

The recommendations that emerged from this project are relevant for other large-scale community projects, particularly in settings with high HIV and STI prevalence rates.

\section{Behavioral change education}

- The MIP should coordinate peer education programs for all target and sub-populations involved in sexual networks in the area.

- The program should examine the effectiveness of promoting condom use among women without a comprehensive program for men, given women's lack of power to negotiate safer sex in many contexts. A greater emphasis on promoting condom use among men may be more effective.

\section{STI treatment}

- It is critical to analyze the pattern of STIs and sexual networks in the community prior to the introduction of interventions.

- To have greater impact on STI prevalence, the MIP should carefully explore different options to address STIs among the regular partners of SWs and among high-risk women in the community. Depending on the levels of infection among high-risk women, these could be included in an expanded PPT program. For regular partners of SWs, a more appropriate approach might be to promote condom use as well as health-care seeking behavior. While it is unlikely that STI treatment interventions will have a significant impact on HIV incidence in population groups where HIV prevalence is already high, such interventions will nevertheless reduce the burden of STIs in the community.

- Attention to quality of STI services should continue to be a key focus of the MIP. Even when services are accessible, clients may not use them due to concerns about the quality of care provided, privacy, and stigma.

- The preventive component of the MIP should be integrated with other community programs focusing on HIV voluntary counseling and testing, care and support, and treatment services.

\section{The role of social organizations}

- The MIP should develop innovative ways to harness the positive aspects and to reduce the negative influences of group membership in social and community organizations. This could involve training organization leaders to share accurate information and advice to their members about HIV/AIDS. 


\section{Hgrizons}

\section{Stakeholder participation and community mobilization}

- The MIP should continue to cultivate partnerships between the community and the private sector, as this relationship is crucial for greater acceptance of the project and its long-term sustainability.

- The MIP should endeavor to develop good governance culture, and the private sector should help develop good project management skills for community stakeholders. 


\section{Introduction}

Carletonville is a relatively poor town with high levels of unemployment and a well-established sex work industry. The town of Carletonville consists of approximately 200,000 people, including 70,000 mine workers working in 12 gold mine shafts (Campbell and Mzaidume 2002). Carletonville was built on the gold mining economy, which heavily depended on migrant workers. Many of the mine workers come from other rural areas of South Africa and neighboring countries. Most mine workers live in single-sex hostels near the mine compounds and usually visit their homes once a year. Surrounding these compounds are "hotspots," establishments where beer and sex are bought and sold. Given the existence of these hotspots and being away from home for long periods of time, these conditions can foster risky sexual behavior among mine workers. The majority of the general population lives in the township of Khutsong and the city of Carletonville. Prior to the transition to democratic rule in South Africa in 1994, the city center and its immediate surroundings were home to a large white population. Since 1994 the area has become more racially mixed.

The Mothusimpilo ("working together for health") Intervention Project (MIP) was launched in 1998 by the Horizons Program, in collaboration with the Center for Scientific and Industrial Research (CSIR), the South African Institute for Medical Research (SAIMR), and the London School of Economics (LSE), to reduce the transmission of HIV and other sexually transmitted infections (STIs) in the mining town of Carletonville. The project aimed to sustain these reductions through enhanced prevention and treatment services. Data collected in 1996 indicated that 4.6 percent of mine workers were infected with syphilis, 6.7 percent were infected with chlamydia, and 8.1 percent were infected with gonorrhea (Ballard 1996). A literature review conducted by the International Organization for Migration in 2003 suggested that migrant workers, many of whom work in mines, and sex workers (SWs) are particularly vulnerable to HIV infection as a result of their high-risk sexual behavior (International Organization for Migration 2003). We hypothesized that focusing interventions on these two groups would reduce the transmission of HIV and have an impact on HIV incidence in the wider community. Thus, the MIP aimed to reduce HIV incidence in the entire community by targeting mine workers and SWs.

\section{Description of the intervention}

The intervention aimed to reduce the incidence of HIV infection by increasing condom use, decreasing the number of sexual partners, and reducing STIs among mine workers and sex workers.

Three key interventions were designed to meet these objectives: behavior change communication through peer education for SWs and mine workers, condom promotion and distribution, and improved management of STIs through strengthening syndromic management in combination with periodic presumptive treatment (PPT) of STIs. The PPT component focused exclusively on self-identified SWs working in areas around the mining compounds.

In planning the intervention, we assumed that focusing on the risky sexual contacts between mine workers and SWs would have an impact on men and women in the larger community. Mine workers and SWs had high transmission rates of both HIV and STIs, and this was likely having an impact on the larger community through extensive sexual networks. Therefore, it was 


\section{Hgrizons}

hypothesized that focusing interventions on these two groups would benefit the whole community by reducing community incidence and prevalence of STIs and the incidence of HIV infection.

\section{I mplementation of the intervention: Challenges and accomplishments}

\section{Peer education}

The first component of the project focused on a behavior change intervention for SWs and mine workers. Peer education activities for SWs commenced in 1998. The key messages that were emphasized were the importance of condom use, the importance of seeking treatment for STIs at health facilities, and the availability of PPT services at mobile clinics.

Peer educators were chosen by the project coordinator from a list of women nominated by the SWs themselves. These women were trained in the following areas: community work, personal health and hygiene, the signs and symptoms of STIs, referral procedures for STI treatment and care, and promotion and distribution of condoms. The peer educator training methodology for SWs was participatory in nature; both drama and role-plays were used. The MIP trained over 150 SWs as peer educators since the inception of the project. Peer educators received a gratuity of R200 per month (approximately US\$30). The outreach coordinator visited peer educators weekly to provide support to their ongoing activities. Peer educators filled in progress sheets recording the number of meetings organized and condoms distributed.

Challenges identified in the implementation of peer education activities for SWs included sustaining interest and motivation over a four-year period. Campbell (2003) remarks on the drop in the number of SWs attending activities due to the tendency for peer educators to use didactic teaching methods rather than participatory methods, the need for fresh material, and the gradual withdrawal of the 'champion' (the outreach coordinator) of the program. Furthermore, efforts to integrate economic empowerment activities into the program were not successful, which also hampered the effectiveness of the behavior change messages. As the project matured, an increasing number of peer educators fell ill and died of HIV/AIDS complications, which meant that the MIP had to recruit and train new peer educators.

A behavior change intervention was also planned for mine workers. The mining companies were to identify mine workers who were interested in being peer educators. This intervention was planned to complement the sex worker intervention. Peer educators were to attend monthly trainings and planning and review meetings organized by the MIP, get time off to conduct activities, and receive a small allowance for providing these services. In the early years of the project, the mining companies tended to pursue their own independent program with little or no connection to the intervention initiated by the MIP. The MIP trained very few peer educators, and those who were trained received little ongoing support, with no follow up after training or monitoring of their activities. In addition, peer educators were not given paid time off to conduct outreach activities, which resulted in activities being conducted in an unsystematic fashion. Trade unions did not make any contribution to or support peer educators beyond identifying initial participants. In the third year of the project, one mine employed a full-time staff member to run its HIV/AIDS activities, but activities continued to be conducted separately from the MIP. This was of concern to the MIP, which had envisaged a more coordinated and synergistic peer education approach for mine workers. Despite setbacks, 185 mine workers from two mining houses were trained as peer educators by the end of the research period. 
At the beginning of the project, two schools in Khutsong invited the MIP to help design a peer education program for their students. Peer education for youth was not in the original design of the project, but the MIP pursued the opportunity as it broadly fell in with the objective to work with the community through behavior change. For this activity, 51 peer educators from the two schools were trained. However, participatory peer education was found to be difficult to implement in the structured school environment where didactic learning styles were more established. In addition, the project targeted youth who were not attending school, which resulted in the training of 17 peer educators who were out of school. The decision of how to implement the peer education program was left up to the individual schools (Campbell and MacPhail 2002). The interventions among youth were sporadic and were not uniformly conducted.

In sum, a systematic peer education program was implemented among SWs, but corresponding programs for mine workers and youth were weaker, far less coordinated, and lacked both coverage and intensity.

\section{Condom distribution}

The second component of the project was condom distribution. The condoms were free of charge to those who wanted them. The mine companies collected government-supplied condoms from the MIP and distributed them through peer educators or appointed individuals in each hostel. Condom distribution among SWs and the Khutsong community at large was undertaken by peer educators, most of whom were SWs. In some circumstances, school-based peer educators were unable to distribute condoms due to restrictions from the school governing boards. Tally sheets kept by peer educators and the project coordinators indicated that over 10 million condoms were distributed from the MIP between 1998 and 2001. These distribution statistics do not necessarily reflect condom use in Carletonville.

\section{Enhanced STI services}

The third component of the project was to strengthen the delivery of quality services for STIs at private and public sector health facilities in Carletonville. Service providers from public and private facilities were trained in syndromic management. The training of providers in syndromic management at Carletonville began in January 1999. The training was initially aimed at nurses at local council clinics, private practitioners, and mine health facilities. By the end of 2000, 94 percent of the 145 nurse providers in the district had received training in the syndromic management of STIs. Initially, private practitioners were not interested in the training, but they were attracted through a continuing medical education (CME) accreditation system. Periodically, doctors are required to participate in medical education as a requirement to continue practicing. Attending the course on STIs allowed them to earn points that counted toward the total requirement. Taking advantage of this arrangement, all 34 doctors in Carletonville attended the first course on STIs in order to fulfill their CME requirement. In addition, 61 of an estimated 200 traditional healers in the area participated in three workshops. The workshops covered sexuality, traditional beliefs about STIs, tuberculosis (TB), care and support for PLHA, partner notification, counseling for behavior change, syndromic management, and referral. Following the training, 30 traditional healers participated in the project. They issued partner notification slips and referrals to public clinics for their patients with STI symptoms. 


\section{Hgrizons}

In February 2000 a PPT program was established to manage frequently asymptomatic STIs in SWs. Each month SWs enrolled in the program were given one gram of azithromycin to treat gonorrhea and chlamydia. The administration of PPT to SWs was facilitated by the use of two mobile clinics that were stationed at various locations around Carletonville. The nurses provided outreach STI services to SWs recruited mainly from "hotspots," the informal settlements, and the township. Since the introduction of the PPT program, approximately 900 SWs have enrolled to receive treatment. To date, this component of the interventions is ongoing and supported by the mines. 


\section{Methodology}

\section{Community-based surveys}

In 1998, prior to the implementation of the intervention, we conducted a baseline survey of SWs, mine workers, men, and women in the community. This was followed by an endline survey with the same study groups in 2001. Sample sizes for each of the groups were based on estimations of HIV and STI prevalence levels. These sample sizes were selected in order to determine if a 30 percent reduction in HIV and STI incidence was detected with statistical confidence.

Before fieldwork was undertaken, the surveys were discussed with management in the mining industry and community leaders in Carletonville city center and Khutsong Township. Field assistants were recruited from the Carletonville community for both surveys. Candidates recruited as selectors were trained for three days, while interviewers were trained for a week using participatory methods. Progressus, the company that was contracted to carry out the surveys, conducted all training.

The number of clusters and people per cluster needed to proportionally represent the variety of housing types ${ }^{1}$ was determined by a demographic survey and aerial photography. The demographic survey was conducted in 1997 and indicated that over 56,000 people lived in Khutsong Township in 18,000 dwellings. Nearly 71,000 mine workers lived in single sex mine hostels in Carletonville. Mine workers, SWs, and the general population of Khutsong were sampled separately. Table 1 illustrates the final samples for the baseline and endline surveys.

Table 1 Sample sizes for baseline and endline surveys, 1998 \& 2001

\begin{tabular}{lcc}
\hline & $\mathbf{1 9 9 8}$ & $\mathbf{2 0 0 1}$ \\
\hline Sex workers (No age restriction) & 121 & 101 \\
Mine workers (No age restriction) & 899 & 994 \\
Men in Carletonville community & 499 & 532 \\
$\begin{array}{l}\text { (13-59 years) } \\
\text { Women in Carletonville community } \\
\text { (13-59 years) }\end{array}$ & 710 & 878 \\
\hline
\end{tabular}

Within Khutsong the population was stratified according to housing type. A multi-stage random and systematic cluster sample was used. Index houses were selected using randomly generated numbers. Clusters were then drawn by systematically selecting every third house from the index house to the right in 1998. The same procedure was adopted in 2001 though the clusters were not necessarily the same for the two years. Once a cluster was marked, the individual houses to be included were described to ensure that selectors identified the correct houses

\footnotetext{
${ }^{1}$ Housing types sampled in the survey included private houses, council houses (usually houses of poorer quality than private, and rented from the local authority), 'site and service' areas (areas with electricity, water, and sanitation services available), council hostels, and informal settlements. In addition, respondents living in backyard shacks and the hotspots around the mines were also represented in the survey.
} 


\section{Hgrizons}

during the survey. Cluster lists and household forms were prepared. Household forms recorded refusals and those houses where no one was found to be home over a five-day period. All males and females between the ages of 13 and 59 years old were asked to participate from each household.

Mine workers occupying every third room to the right of a randomly selected index room in each of the 10 hostels were asked to participate in the survey. Recruitment began in the early afternoon following the completion of the evening shift and continued throughout the afternoon. Sampling was conducted until 90 men had been recruited from each hostel.

SWs living in "hotspots" were randomly selected after peer educators provided a list of all inhabitants. Based on this information, around 100 participants were drawn from a hat.

Informed consent forms were translated into local languages and were obtained for questions related to demographics, health and health care seeking behavior, sexual behavior, and urine and blood samples. Participants were given 10 rands $^{2}$ to cover the cost of returning for the results of blood tests. A more detailed description of the methodology can be found in earlier papers (Gilgen et al. 2000, Williams and Campbell 1999).

During this survey, respondents completed a face-to-face questionnaire based on the UNAIDS multi-site HIV survey (Buve et al. 2001). The questionnaire was adapted to suit both the aims of the survey and the conditions. The questionnaires were translated into four local languages: Xhosa, Zulu, Sotho, and Tswana. The instruments were back translated to verify accuracy of the translations. The questionnaires in 1998 and 2001 covered the following key topics:

- Background characteristics

- Demographic and socioeconomic issues

- Measures of social capital

- Sexual relationships and sexual networking with both regular and casual partners

- Knowledge and perceptions of HIV/AIDS

- Attitudes toward people who are HIV-positive

- Condom use and reported behavior change

- Experience with STIs

Blood and urine samples were collected from participants after obtaining informed consent from each participant. During data collection, participants were given information about obtaining their HIV status. They were referred to relevant health facilities in order to receive pre- and post-test HIV counseling and HIV services.

Blood and urine samples were transported to a laboratory in Johannesburg for testing. The blood was tested for HIV using a single Capillus ${ }^{\circledR}$ HIV-1/HIV-2 Latex Aggregation test. HIV incidence was to be calculated on the basis of the results of a detuned ELISA (Schwarcz 1999). Ultimately, this test was not used because of questions about its usefulness in this context to measure recent seroconversions. Therefore, the findings do not include HIV incidence.

Two tests were conducted for syphilis, a non-treponemal carbon antigen test and the ImmutrepCarbon Antigen. The LCx ${ }^{\circledR}$ Neisseria gonorrhea assay was used to test for gonorrhea and the $\mathrm{LCx}{ }^{\circledR}$ Chlamydia trachomatis assay for chlamydia.

${ }^{2}$ US\$1.00 $=6.5$ rands in September 1998 and 8.3 rands in September 2001 


\section{Qualitative assessment of STI services}

Two assessments of the quality of care of STI services were conducted in Carletonville. The first, conducted in 1999, was followed by a more detailed assessment in 2000. Both assessments addressed quality of STI services, but due to differences in data collection methodologies and sample sizes, it was not possible to compare all data items. For example, the 1999 assessment used three methods of data collection: simulated clients presenting complaints characteristic of vaginal and urethral discharge, interviews, and focus group discussions (FGDs) with providers and clients (Harrison and Ntuli 1999). The sample size in 2000 was larger, and data collection included the observation of interactions between providers and clients and a review of clients' records at health facilities. Despite differences in the assessments, selected results are presented in this report and, where possible, comparisons are made to give insights into the quality of STI services in Carletonville.

The 2000 assessment was conducted to evaluate infrastructure readiness to provide STI care in both public and private settings and to assess the knowledge of providers and their training needs. In addition, quality of care provided and client satisfaction with services were also assessed. Data were collected through client observations and exit interviews in the public sector and through exit interviews in the private sector and with traditional healers. In-depth interviews (IDIs) and FGDs were conducted with service providers. Table 2 depicts the methods used and the sample sizes. 


\section{Hgrizons}

Table 2 Population and sample of health facilities

\begin{tabular}{|c|c|c|}
\hline Source of data & Data collection method & Sample size \\
\hline Public clinics & & 7 \\
\hline Providers & Interviews & 13 \\
\hline Clients & FGDs & 3 \\
\hline Clients & Observation and exit interviews & 32 \\
\hline Providers & FGDs & 1 \\
\hline Mine clinics & & 1 \\
\hline Providers & Interviews & 5 \\
\hline Clients & FGDs & 1 \\
\hline Clients & Observation and exit interviews & 10 \\
\hline Providers & FGDs & 1 \\
\hline \multicolumn{3}{|l|}{ Traditional healers } \\
\hline Providers & FGDs & 2 \\
\hline Clients & In-depth interviews & 16 \\
\hline Clients & FGDs & 1 \\
\hline Private general practitioners & & 17 \\
\hline Providers & In-depth interviews & 12 \\
\hline Clients & Not available & Not applicable \\
\hline
\end{tabular}

\section{The role of social organizations}

An analysis of social organizations was conducted in 2001. The objectives of this analysis were to describe social organizations in Carletonville and the role they play in fostering risky and preventive behaviors. Group members were selected to participate in IDIs and FGDs. Table 3 provides details on the sample and data collection methods used. Data were analyzed using thematic analysis. In addition, the researchers used the survey data to examine the associations between membership in social organizations and risky sexual behavior and HIV prevalence. 
Table 3 Distribution of FGDs and IDIs by organization

\begin{tabular}{|c|c|c|c|c|}
\hline \multirow[b]{2}{*}{ Organization } & \multicolumn{2}{|c|}{ Focus group discussions } & \multicolumn{2}{|c|}{ In-depth interviews } \\
\hline & Male & Female & Male & Female \\
\hline Stokvel & 1 & 1 & 1 & 1 \\
\hline Burial society & 1 & 1 & 1 & 1 \\
\hline Church group & 1 & 1 & 0 & 1 \\
\hline Political organization & 1 & 1 & 1 & 1 \\
\hline Sports group & 1 & 1 & 1 & 1 \\
\hline Women's group & $\mathrm{n} / \mathrm{a}$ & 1 & $\mathrm{n} / \mathrm{a}$ & 2 \\
\hline Subtotal & 5 & 6 & 4 & 7 \\
\hline Total & \multicolumn{2}{|c|}{11} & \multicolumn{2}{|c|}{11} \\
\hline
\end{tabular}

\section{Sexual networking among sex workers}

Qualitative data on sexual behavior and partnerships among SWs in Carletonville were collected in 2001. Four FGDs and 24 in-depth interviews were conducted with SWs from four areas. 


\section{Hgrizons}

\section{Findings}

The report synthesizes the findings from the research activities described in the previous section in an effort to present an integrated picture of the intervention, its impact, and lessons learned from this intervention project.

\section{Description of the Carletonville study population}

This section provides a brief description of the characteristics of SWs, mine workers, men, and women in the community drawn from data collected in the 1998 and 2001 surveys.

\section{Female sex workers}

On average, SWs were in their early thirties, had some education (mostly at a primary level), and were primarily Sotho or Xhosa speakers. SWs tended to have a low monthly income (see Table 4), with their monthly mean income increasing from R464 (1998) to R605 (2001). ${ }^{3}$ In areas surrounding the mines, many of the women were SWs, but in more established communities in town, retired SWs sold alcohol. Approximately 40 percent of the SWs considered themselves to be migrants, and almost all the women were born in another area. Ten percent of the women were born in another country. The qualitative study substantiated that many SWs came to Carletonville specifically for employment and remained a fairly mobile population. In both studies, SWs had lived in Carletonville between five and seven years. Less than 40 percent of women reported taking a trip in the last twelve months in both surveys (39 percent and 36 percent respectively), to urban or rural areas outside Carletonville.

Reported alcohol use increased between 1998 and 2001 from 59 percent to over 80 percent. However, in both surveys just over a quarter of women reported that they drank alcohol daily. From the qualitative discussions, alcohol is used to prevent tiredness and to overcome fear, though SWs also mentioned that alcohol use resulted in unprotected sex.

\section{Mine workers}

On average, mine workers were in their mid- to late-30s and had some education (57 percent in 1998 and 66 percent in 2001). A high percentage of mine workers considered themselves to be migrants, 97 percent (1998) and 90 percent (2001). Most mine workers were not born in Carletonville. Many of the mine workers came from other parts of South Africa and other African countries. Comparing 1998 and 2001, 66 percent and 57 percent of the respondents had made a trip out of Carletonville 12 months before the survey. On average, mine workers' monthly incomes had increased from R1,335 (1998) to R1,690 (2001). Mine workers were well paid in the local context. This earning power made mine workers attractive sexual partners (see Table 4).

\footnotetext{
${ }^{3}$ US\$1.00 $=6.5$ rands in September 1998 and 8.3 rands in September 2001
} 


\section{Women in Khutsong}

Women interviewed from the Khutsong community were on average 30 years old. A majority of them were educated at the primary school level (61 percent in 1998 and 59 percent in 2001). A higher proportion of women surveyed in 2001 (43 percent) were born in Carletonville than in 1998 (32 percent). The percentage of women who said that they were migrants decreased from 21 percent in 1998 to 13 percent in 2001. Similarly, a smaller proportion had made a trip out of Carletonville in the last twelve months, with this percentage decreasing from 41 percent to 28 percent. On average, women in the community earned less in 2001 than in 1998, with monthly income decreasing from R267 to R250.

\section{Men in Khutsong}

The average age of males in Khutsong was mid- to late-20s, and most of them had attended primary school (58 percent in 1998 and 56 percent in 2001). A higher proportion of men surveyed in 2001 were born in Carletonville (55 percent compared to 42 percent in 1998). Consistent with findings on women, a smaller proportion of men reported that they were migrants in 2001 (17 percent) than in 1998 (31 percent). In addition, fewer men had taken a trip out of Carletonville in the last twelve months (from 50 percent to 29 percent). On average, men's monthly incomes had decreased from R534 in 1998 to R430 in 2001.

The populations surveyed were relatively young and stationary. This could indicate that Carletonville was becoming a more stable community. As previously discussed and shown in Table 4, the level of reported income fell over the three-year period. Although SWs earnings increased slightly, their incomes, and those of men and women in the community, remained low. In contrast, mine workers earned substantially more than other groups in Carletonville, and their salaries kept pace with industry and minimum wage standards. It is apparent that women in the community were economically vulnerable.

Table 4 Average incomes for 1998 and 2001 for men and women in Khutsong, mine workers, and sex workers

\begin{tabular}{lcccc}
\hline Average income per month & Men & Women & Mine workers & SWs \\
\hline 1998 & R534 & R267 & R1,335 & R464 \\
& $(n=491)$ & $(n=694)$ & $(n=896)$ & $(n=121)$ \\
2001 & R430 & R250 & R1,690 & R605 \\
& $(n=532)$ & $(n=878)$ & $(n=991)$ & $(n=100)$ \\
\hline
\end{tabular}

\section{HIV/ AI DS knowledge}

Information was gathered on knowledge of HIV/AIDS by questioning individuals about how they could protect themselves from HIV infection. Responses indicated that the overwhelming majority of respondents understood how HIV is transmitted and the steps to take to prevent infection.

Table 5 presents the data that were collected on knowledge of HIV/AIDS. Among SWs, 88 percent indicated that using condoms during sexual intercourse was protective in 1998, and this 


\section{Hgrizons}

figure increased to 98 percent in 2001. Given that knowledge levels were already high, there was only a small increase (six percentage points) in the proportion of SWs who mentioned that it was important to remain faithful to one partner. Some participants understood that individuals could be HIV-positive without showing signs of being sick, but the proportion that knew this was not as high as expected. Participants were asked if HIV could be transmitted through touching and sharing food with an HIV-positive individual. Over the three-year period, knowledge levels related to these two issues increased. For example, mine workers' knowledge about not becoming infected by touching an HIV-positive individual increased from 48 percent to 70 percent.

In the context of widespread HIV/AIDS messages from many sources, it is not possible to attribute increases in knowledge to only MIP IEC activities. High levels of knowledge of HIV/AIDS in the general population have been reported in findings from most behavioral surveys conducted in South Africa (HSRC/NMCF 2002, DHS 1998).

\section{Sexual behavior}

Information was gathered on condom use with regular partners (defined as partners the respondent was married to or lived with) and with casual partners (sexual partners the respondent did not live with). Table 6 shows the results from the 1998 and 2001 surveys.

In 1998 less than half (45 percent) of SWs said that they had made changes in their lives to combat HIV infection; this had significantly increased to 64 percent in 2001. It was disappointing, however, that the percentage of SWs reporting consistent condom use dropped from 70 percent to 59 percent. Due to the nature of sex work, it was unrealistic to expect SWs to reduce the number of sexual partners, unless the intervention focused on alternative means for them to earn an income. Only 11 percent of SWs reported that they had reduced the number of sexual partners they had in 2001 compared to 17 percent in 1998. Condom use with their last casual partner remained unchanged at 59 percent. The women who indicated that they were using condoms said they were doing so to prevent contracting or transmitting an STI. These women were not using condoms as a form of dual protection (pregnancy avoidance and protection from STIs). Fifty-three percent of the SWs were using contraceptives, primarily injectables. Of concern was that the percentage of SWs using condoms with their regular partners decreased from 26 percent in 1998 to 12 percent in 2001.

In the early years of the project, peer education among mine workers was sporadic and therefore changes in this group should not be attributed entirely to MIP interventions. As seen in Table 6, in 1998, 53 percent of mine workers reported having had at least one casual partner in the last 12 months before the survey. This figure decreased significantly to 43 percent three years later. Very few mine workers reported always using a condom with their regular partner (only 6 percent in 1998 and 4 percent in 2001). A higher proportion of mine workers reported always using a condom with their casual partners in 2001 compared to 1998, but the 2001 figure represents only about a fourth of respondents with casual partners. The proportion of mine workers reporting that they had made changes in their lives to avoid contracting HIV/AIDS remained nearly constant (37 percent and 41 percent) between the two surveys. 
Table 5 Changes in HIVIAIDS knowledge among sex workers, mine workers, men, and women in the community for years 1998 and 2001

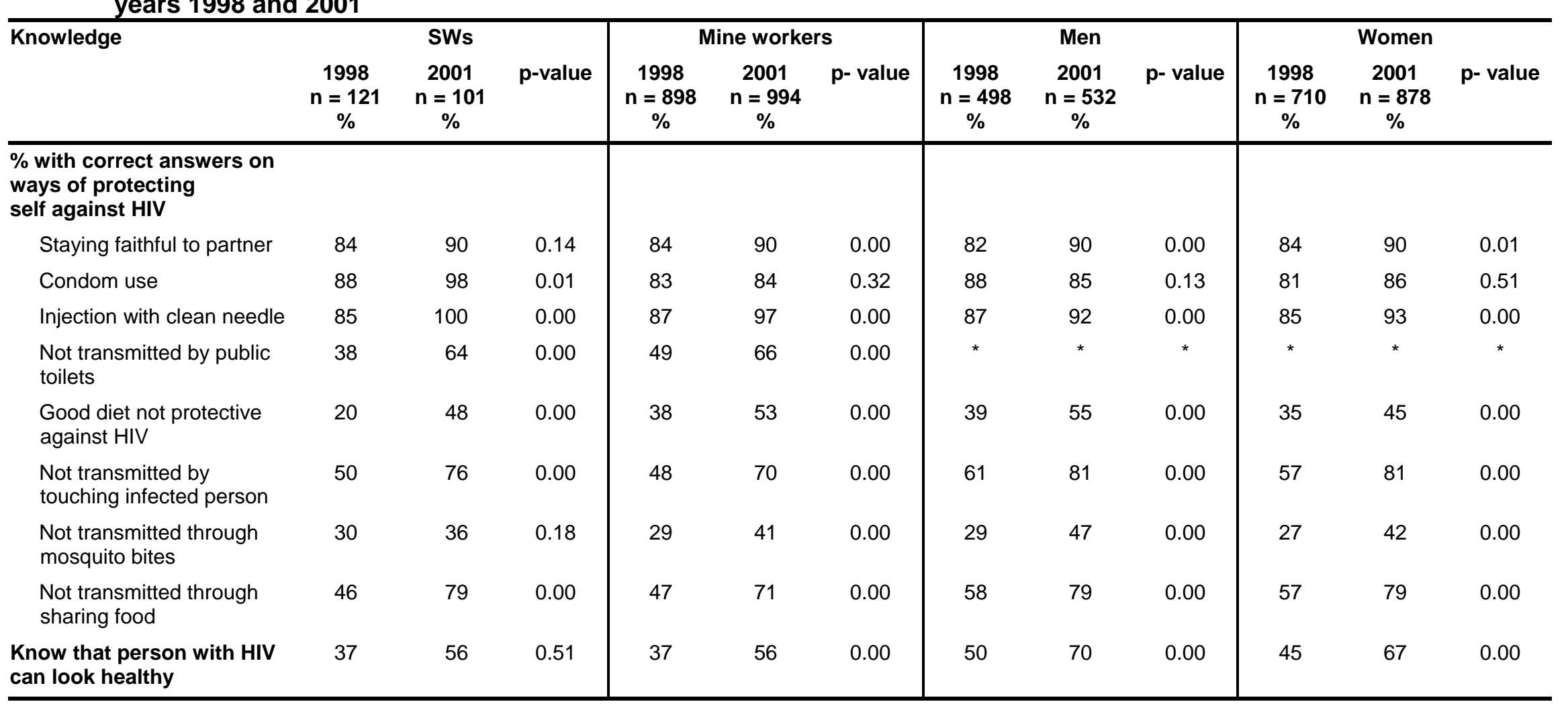

* Missing data 
Table 6 Changes in behavior of sex workers, mine workers, men, and women in the community for years 1998 and 2001

\begin{tabular}{|c|c|c|c|c|c|c|c|c|c|c|c|c|}
\hline \multirow[t]{2}{*}{ Behavior } & \multicolumn{3}{|c|}{ SWs } & \multicolumn{3}{|c|}{ Mine workers } & \multicolumn{3}{|c|}{ Men } & \multicolumn{3}{|c|}{ Women } \\
\hline & $\begin{array}{c}1998 \\
n=121\end{array}$ & $\begin{array}{c}2001 \\
n=101\end{array}$ & $p$-value & $\begin{array}{c}1998 \\
n=898\end{array}$ & $\begin{array}{c}2001 \\
n=994\end{array}$ & $p$-value & $\begin{array}{c}1998 \\
n=498\end{array}$ & $\begin{array}{c}2001 \\
n=532\end{array}$ & $p$-value & $\begin{array}{c}1998 \\
n=710\end{array}$ & $\begin{array}{c}2001 \\
n=878\end{array}$ & p-value \\
\hline $\begin{array}{l}\text { Made changes in your } \\
\text { life (\%) }\end{array}$ & 45 & 64 & 0.00 & 37 & 41 & 0.04 & 29 & 21 & 0.00 & 30 & 21 & 0.00 \\
\hline $\begin{array}{l}\text { Use a condom } \\
\text { always }\end{array}$ & 70 & 59 & ns & 19 & 26 & 0.02 & 29 & 36 & ns & 29 & 28 & 0.37 \\
\hline $\begin{array}{l}\% \text { with casual partner } \\
\text { in last } 12 \text { months }\end{array}$ & - & - & - & 53 & 43 & 0.00 & $\begin{array}{c}37 \\
(430)\end{array}$ & 45 & ns & $\begin{array}{c}24 \\
(650)\end{array}$ & 41 & 0.00 \\
\hline \multicolumn{13}{|l|}{$\begin{array}{l}\text { Condom use with } \\
\text { casual partners (\%) }\end{array}$} \\
\hline Always & 59 & 59 & ns & 19 & 24 & 0.02 & 28 & 37 & 0.04 & 22 & 25 & 0.26 \\
\hline \multicolumn{13}{|l|}{$\begin{array}{l}\text { Reasons for condom } \\
\text { use (\%) }\end{array}$} \\
\hline Avoid disease & 93 & 92 & ns & 85 & 82 & ns & 73 & 70 & ns & 69 & 62 & 0.26 \\
\hline \multicolumn{13}{|l|}{$\begin{array}{l}\text { Condom use with } \\
\text { regular partners (\%) }\end{array}$} \\
\hline Always & 26 & 12 & ns & 6 & 4 & ns & 9 & 6 & ns & 6 & 5 & ns \\
\hline
\end{tabular}

*Data not analyzed for sex workers as their clients are predominantly casual partners 
In contrast to SWs, where the largest proportion cited condom use as the change they had instituted in their lives, the majority of mine workers cited reduction of partners as a step that they had adopted.

For both men and women in the community, a smaller percentage reported that they had made changes in their lives because of HIV/AIDS at the second survey compared to the first survey. For those who had made changes, the most common response was that they now used condoms consistently. For both men and women, there was an unexpected increase in the percentage of individuals reporting a relationship with a casual partner in the 12 months prior to the survey. The increase for women in the community was from 24 percent to 41 percent.

Overall observations suggest that there were elements of reported behavior change for some groups in Carletonville, but the pattern is mixed and sometimes in an unexpected direction. After three years of the project, a greater proportion of mine workers declared that they had made changes in their lives to avoid HIV/AIDS and that they used condoms consistently with casual partners. Sixty-four percent of SWs declared in 2001 that they had changed their behavior to avoid contracting HIV/AIDS, but actual behavior change was not clearly seen. In the general community, where there were no interventions, an increase in some risky behaviors was noted.

\section{Sexually transmitted infections and HIV}

Urine and blood specimens were collected from each consenting study participant to test for HIV, syphilis, gonorrhea, and chlamydia. A negligible number of participants refused to be tested, mainly due to conflicting engagements. Figures 1 and 2 illustrate the results of HIV prevalence by age for 1998 and 2001. Table 7 shows overall STI prevalence for all the groups in Carletonville.

HIV prevalence among mine workers increased from 29 percent to 36 percent. HIV prevalence also increased among SWs (69 percent to 78 percent) and among women in the community (37 percent to 45 percent). There was a slight decrease of HIV prevalence among men in the community (22 percent to 20 percent).

Figure 1 shows HIV prevalence by age for each group for 1998, while Figure 2 indicates prevalence levels for 2001. From these graphs emerges a consistent pattern of changes in HIV prevalence levels associated with age and gender. For each group there is a general rise in the prevalence of HIV up to age group 30 to 34 years, after which it tapers off gradually as age increases. The graphs emphasize the differences in the prevalence levels for the groups; SWs have the highest levels for each age group, followed by women in the community. Data from 2001 indicate that in the younger age groups, males in the community have lower HIV prevalence than mine workers. Between the ages of 29 to 34 years, prevalence for males outpaces that of mine workers. This could be related to marital status and the age and onset of sexual relations for mine workers and men in the community.

A key objective of the intervention in Carletonville was to reduce the prevalence of HIV infection and reduce the prevalence of STIs. Except for men in the community, the HIV prevalence for each group increased over the three years of the project. For other STIs, results 


\section{Hgrizons}

Figure 1 HIV prevalence by age for mine workers, SWs, men, and women in the community in 1998

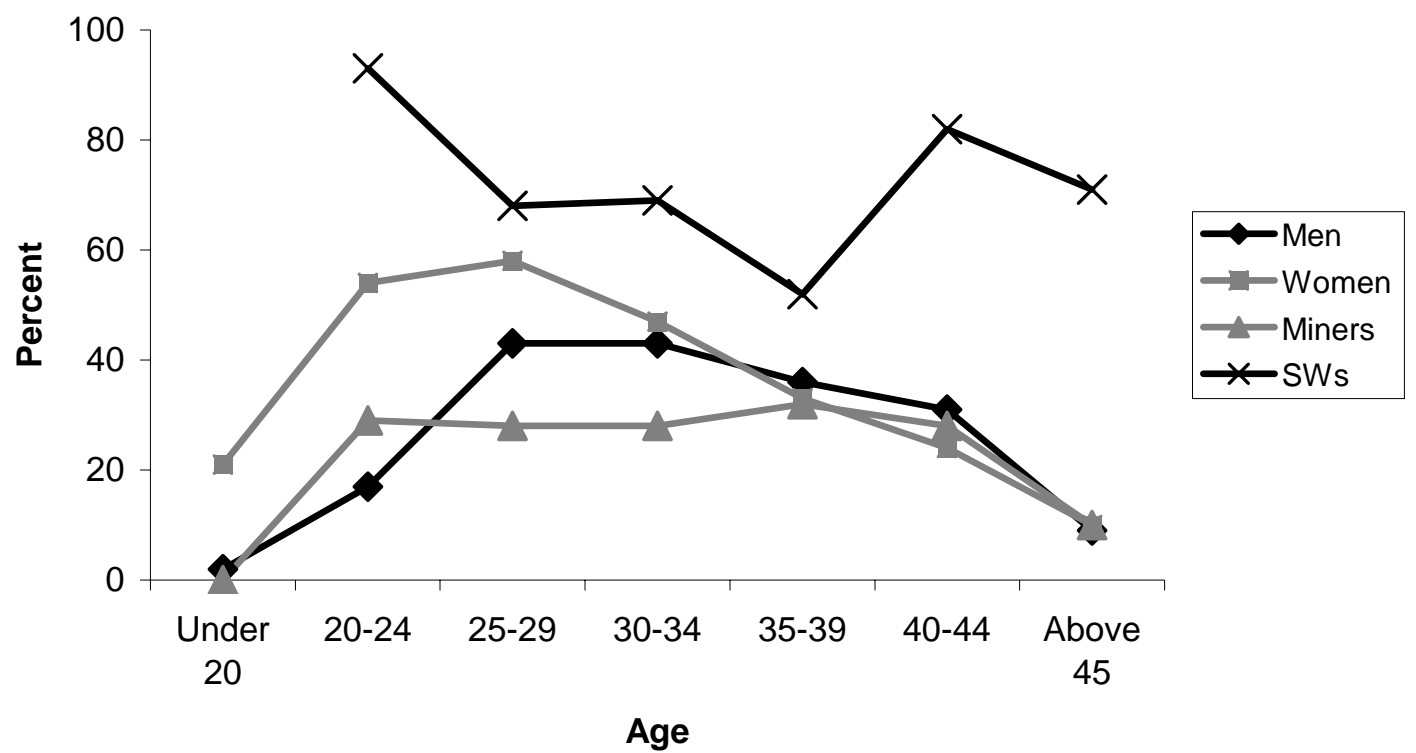

Figure 2 HIV prevalence by age for mine workers, SWs, men, and women in the community in 2001

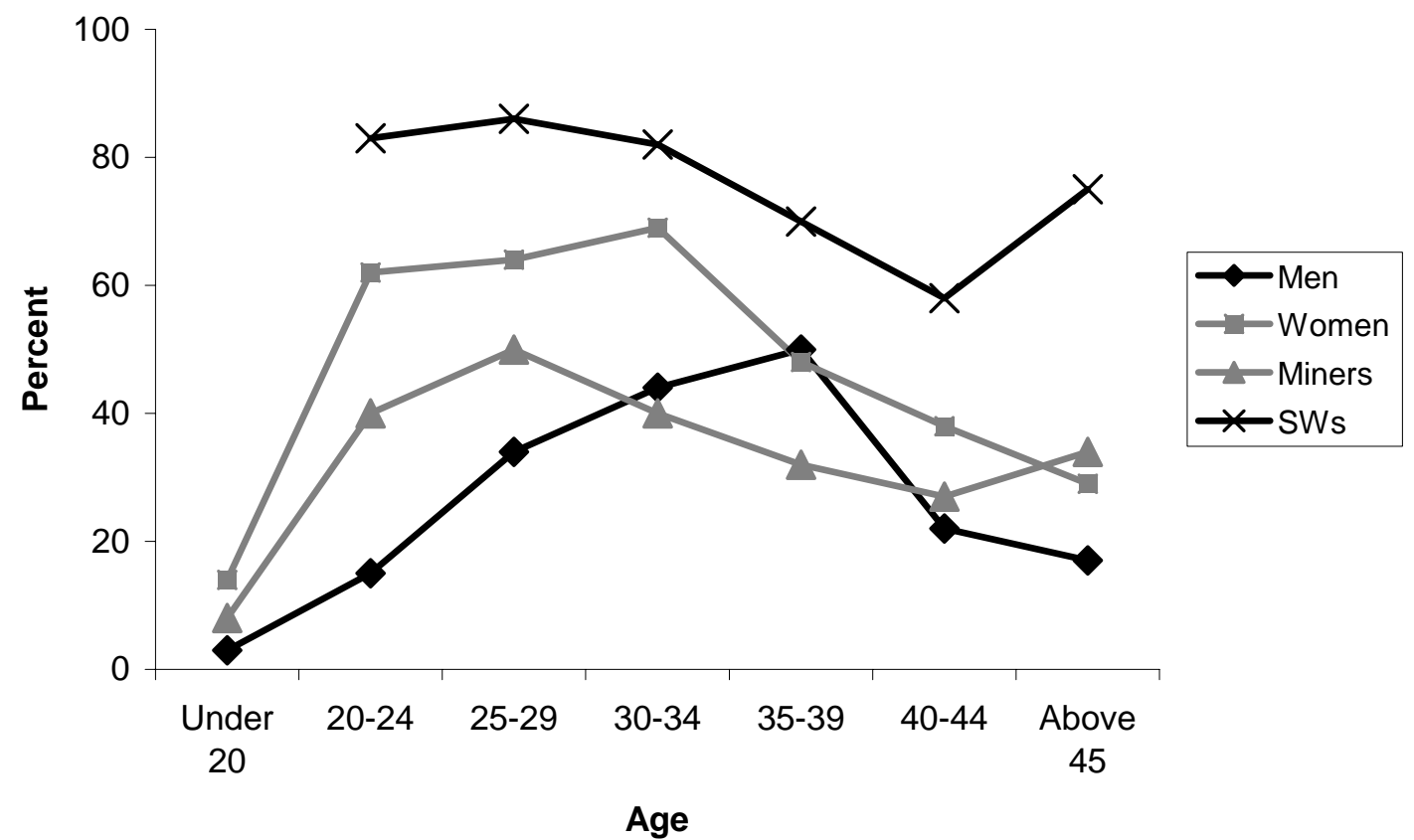


Table 7 Changes in prevalence of STIs among sex workers, mine workers, men, and women in the community for years 1998 and 2001

\begin{tabular}{|c|c|c|c|c|c|c|c|c|c|c|c|c|}
\hline & \multicolumn{3}{|c|}{ SWs } & \multicolumn{3}{|c|}{ Mine workers } & \multicolumn{3}{|c|}{ Men } & \multicolumn{3}{|c|}{ Women } \\
\hline & $\begin{array}{c}1998 \\
n=121 \\
\%\end{array}$ & $\begin{array}{c}2001 \\
n=101 \\
\%\end{array}$ & $p$-value & $\begin{array}{c}1998 \\
\mathrm{n}=898 \\
\%\end{array}$ & $\begin{array}{c}2001 \\
\mathrm{n}=994 \\
\%\end{array}$ & $p$-value & $\begin{array}{c}1998 \\
n=498 \\
\%\end{array}$ & $\begin{array}{c}2001 \\
n=532 \\
\%\end{array}$ & $p$-value & $\begin{array}{c}1998 \\
n=710 \\
\%\end{array}$ & $\begin{array}{c}2001 \\
\mathrm{n}=878 \\
\%\end{array}$ & $p$-value \\
\hline \multicolumn{13}{|c|}{ STI prevalence } \\
\hline HIV & 69 & 78 & 0.10 & 29 & 36 & 0.00 & 22 & 20 & 0.26 & 37 & 45 & 0.00 \\
\hline Syphilis & 25 & 21 & 0.22 & 6 & 4 & 0.07 & 6 & 5 & 0.29 & 10 & 13 & 0.05 \\
\hline Chlamydia & 9 & 8 & 0.48 & 4 & 5 & 0.05 & 5 & 7 & 0.17 & 8 & 12 & 0.01 \\
\hline Gonorrhea & 16 & 10 & 0.14 & 3 & 4 & 0.27 & 3 & 4 & 0.32 & 7 & 11 & 0.01 \\
\hline HSV-2 & & 62 & & & 63 & & & 42 & & & 71 & \\
\hline
\end{tabular}




\section{Hgrizons}

chlamydia, and gonorrhea. ${ }^{4}$ This observation was also true for mine workers and males in the community. Among women in the community, there were significant increases in the prevalence of syphilis ( 10 percent to 13 percent, $\mathrm{p}=0.05$ ), chlamydia (8 percent to 12 percent, $p=0.01$ ), and gonorrhea ( 7 percent to 11 percent, $p=0.01$ ). These results are consistent with increases in reported risky behavior in terms of increased number of casual sexual partners and a low percentage of women always using condoms with their casual partners.

\section{Health-seeking behavior and utilization of STI services}

In 1998 nine percent of men reported a symptom of an STI compared to 13 percent in 2001. For mine workers, 12 percent reported they had symptoms of an STI in 1998 and 11 percent in 2001. Similarly for SWs, the figure stayed around the same: 12 percent and 13 percent. For women, the figure increased slightly, from nine percent in 1998 to 14 percent in 2001.

Quantitative data were collected from respondents about where they sought advice when they discovered symptoms of an STI. Respondents reporting a symptom of an STI used the services of hospitals, private practitioners, mobile clinics, and traditional healers. For all groups except SWs, there was no change in the percentage of individuals seeking advice from traditional healers (17 percent for men, 9 percent for women, 16 percent for mine workers). For SWs, there was a decrease from 14 percent to 6 percent between 1998 and 2001. Over the three years, there was a general increase in the use of clinics and hospitals for all groups, though it was most pronounced among women in the community (48 percent to 68 percent) compared to mine workers ( 40 percent to 51 percent), men in the community (40 percent to 51 percent); and SWs (50 percent to 56 percent). The use of general practitioners remained relatively unchanged for mine workers ( 45 percent to 43 percent) and men in the community ( 25 percent to 22 percent) but decreased drastically for SWs (31 percent to 4 percent) and women in the community (23 percent versus 13 percent). The availability of mobile facilities through the MIP increased access to services for SWs; as a result, the proportion of SWs using mobile clinic services increased from 5 percent in 1998 to 61 percent in 2001. In addition, the mobile services where the consultation was free may have attracted SWs away from general practitioners.

Friends and relatives proved to be an important source of information on STIs. A quarter to a third of all respondents who had an infection in the last 12 months had asked a friend or relative for advice in 2001. The proportion of men asking for advice from these sources increased from 28 percent to 35 percent and among mine workers it increased from 10 percent to 22 percent. For SWs, results were similar for the two surveys while among women in the community, it decreased from 35 percent to 28 percent.

\section{Quality of STI services in Carletonville}

This section is based on two qualitative assessments conducted in 1999 and 2000 at public health facilities, health facilities of private practitioners, and mine clinics. This analysis examined the quality of STI services with respect to facilities and supplies; patient consultations; treatment of STI syndromes; and waiting times, privacy, and client satisfaction.

\footnotetext{
${ }^{4}$ The small number of sampled sex workers make it difficult to determine statistical significance though there is an indication of a downward trend in STI levels except HIV.
} 


\section{Facilities and supplies}

Based on findings from both assessments, health facilities were well equipped to provide STI services. All facilities had at least one professional service provider trained in syndromic management, and protocols were available in both the private and public sectors. In the five facilities visited in 1999, no IEC materials were displayed, but in the larger assessment in 2000, all of the facilities had IEC materials that included messages on HIV/AIDS. It was noted in 1998 that four out of the five clinics did not have specula, and in 2001 about 75 percent of the clinics did not have specula.

\section{Patient consultations}

A detailed history was taken from 94 percent of patients in 2000 compared to 92 percent the previous year. There was a marked improvement in the proportion of patients receiving a physical examination of the genitalia (96 percent compared to 62 percent). In addition, results of the physical examination were told to 85 percent of clients in 1999. This figure was 100 percent in 2000.

Ninety-four percent of consultations in 2000 included discussions on condom use compared to 61 percent in the previous year. This could be due to the training that was provided to service providers about the importance of condom use and the protection that condoms provide against STIs. In 2000, 69 percent of clients reported that providers demonstrated proper use of a condom; this was up from 15 percent in 1999. However, exit interviews showed that the number of patients given condoms remained steady, at 44 percent in 2000 compared to 46 percent in 1999.

The importance of partner treatment was discussed in both assessments, and there was no change in the number of providers discussing it with their clients. Discussion on the importance of partner treatment was covered in 84 percent of consultations in 2000 and a similar proportion (85 percent) the previous year. Partner notification cards were given to 69 percent of clients with a syndrome both in 1999 and 2000. These figures were based on collection of partner notification cards given to index clients.

\section{Treatment of STI syndromes}

In 1999 an analysis of treatment effectiveness examined only whether the correct drugs were prescribed for treating selected syndromes, while the 2000 assessment also assessed whether the dosage of the drug and duration of the treatment were correctly prescribed.

In the 2000 assessment, all patients with a syndrome received some treatment compared to only 85 percent in the first assessment. However, the 2000 assessment also showed that there were cases of overprescribing of medicines and that drug prescriptions were being given for viral STIs that did not require drug treatment.

In 2000 the data demonstrated an increase in the proportion of STIs that were diagnosed as genital ulcer disease syndromes compared to the previous year. Since urethral discharge and vaginal discharge syndromes tended to be treated better according to the standard treatment guidelines than other syndromes, the overall proportion of syndromes treated effectively from one evaluation to the next may reflect the change in the syndrome mix seen. However, when only effectiveness of treatment for urethral discharge for the two years is compared, the results 


\section{Hgrizons}

suggest some improvement. In the public sector, there appears to be an improvement from 71 percent of urethral discharge syndromes treated in 1999 compared to 87 percent in 2000. In the private sector, there was no correct treatment of urethral discharge syndromes in 1999, while in 2000 two out of three patients were correctly treated.

It is difficult to compare the proportion of women correctly treated according to national guidelines for vaginal discharge for the two years, as the number of vaginal discharge syndromes seen in 1999 and 2000 were low. In the first evaluation, none of the patients with vaginal discharge were treated correctly at private sector clinics. However, in the second year, one out of two clients were treated appropriately.

\section{Waiting times, privacy, and client satisfaction}

Long waiting times were a contentious topic with patients seeking health services. The 1999 assessment showed that the majority of clients waited less than 20 minutes before being seen by a provider. In FGDs in 2000, the issue of long waiting times was raised by the participants. The average waiting time, according to patients' own estimates, was two hours. On average, in 1999 consultations with patients were reported to have lasted more than 10 minutes, and this figure was 20 minutes a year later (perhaps an indication of improved quality of care). There were no clear reasons for the variation in waiting and consultation times between the two assessments.

In 1999, 92 percent of males and 100 percent of females reported appropriate levels of privacy during their consultations. In 2000 observers reported that 98 percent of consultations were conducted in private. This high percentage was confirmed by reports from clients.

In 1999, 30 percent of respondents reported the quality of their consultation as poor or unsatisfactory; a year later 100 percent of the patients expressed satisfaction with their consultations. Though the quantitative survey in 2000 showed overall satisfaction, this is in contrast with results from FGDs that highlighted extensive dissatisfaction. Such contradictions have been noted in many situation analysis studies in Africa. ${ }^{5}$

A comparison of key indicators between 1999 and 2000 suggests improvement in a number of areas, some more marked than others. Although both the public and private facilities seem well prepared to offer syndromic management to clients in terms of physical facilities, staffing, supplies, and equipment, in practice the project goal of achieving 90 percent syndromic management for all STI patients was only achieved for the treatment of male urethral discharge in public sector facilities. Almost all providers in both the public and private facilities (excluding traditional healers) were trained in syndromic management. Routine data compiled by the National Health Laboratory Services of the University of Witwatersrand (National Institute for Communicable Diseases 2001) on condom distribution and partner notification show that more condoms were being distributed and that more partners were getting treated with shorter delays.

The need to address STI care in the private sector remains a problem and requires a broader national approach exploring regulatory issues and the role of the private sector in STI care. Many private practitioners report that economic considerations drive their prescribing practices,

\footnotetext{
${ }^{5}$ For example, see summaries in Miller, Kate et al. (eds.). 1998. Clinic-Based Family Planning and Reproductive Health Services in Africa: Findings from Situation Analysis Studies. Population Council and United States Agency for International Development (USAID).
} 
which suggests that perhaps training general practitioners at the local level will have little impact on the quality of patient care in the private sector.

Clarification of treatment of warts, herpes, and buboes is necessary in future provider training. Genital ulcers are commonly seen in the public sector as well as the private sector and are frequently not treated according to government protocols. Rational drug use and overprescription in the public sector remain problems, and these have budgetary implications. This could be viewed as a general problem associated with syndromic management in general, especially for women with vaginal discharge syndrome where the specificity of the syndromic approach in identifying cervical infections remains low.

Drug shortages were highlighted in the 1999 assessment, such as clinics running low on metronidazole, a first line drug for vaginal discharge. These issues were addressed satisfactorily by 2000; only 2 out of 19 clinics were out of stock of metronidazole at the time of second evaluation, and the other STI drugs were in stock.

\section{Sexual networks in Carletonville}

The role of sexual networks in Carletonville was investigated to gather additional information to better understand the high levels of STIs and HIV that were detected in 2001, three years after the initiation of the MIP. The literature suggests that the study of sexual networks provides insights into disease transmission patterns, helps identify risk factors for disease acquisition, and helps create targeted prevention strategies (Boiley et al. 2000, Morris 1997). A study of sexual networks also provides a wider focus for understanding risk for different community members and how individuals can be affected by the behavior of others in the same network.

The detected sexual networks in Carletonville are represented in Figure 3. This figure shows the relationships between SWs, mine workers, males, and females in the community. Though these groups tend to live in different geographical areas, there are common meeting places, which facilitate easy contact. For instance, the city entertainment areas that consist of bars, restaurants, and hotels bring many people together. At these places relations are formed between different Carletonville groups. In the community, the "invisible SWs" interact not only with males from the community but also with mine workers, as shown in Table 8.

The MIP was based on the assumption that the epidemic in the mining community was sustained at high levels due to continued transmission through unprotected sexual intercourse from SWs (a population with high levels of STI/HIV) to a lower HIV prevalence, yet high-risk population, mine workers. Furthermore, mine workers were believed to then be transmitting STI/HIV to women in the community, and these women then transmitted STI/HIV to the men in the community. It was postulated that a combined behavior change communication and STI control intervention targeting SWs and mine workers would be a cost-effective way of reducing incidence, and thus prevalence in the mine workers and also in the wider Carletonville community.

The interventions were based on the assumption that sexual relationships were essentially between mine workers and SWs, but both qualitative and quantitative data showed that this was not the case. In 1998, 53 percent of mine workers had sex with a casual partner compared with 43 percent in 2001 in the 12 months prior to the survey. In 1998, 67 percent of these partners 


\section{Hgrizons}

Figure 3 Mapping sexual networks in Carletonville

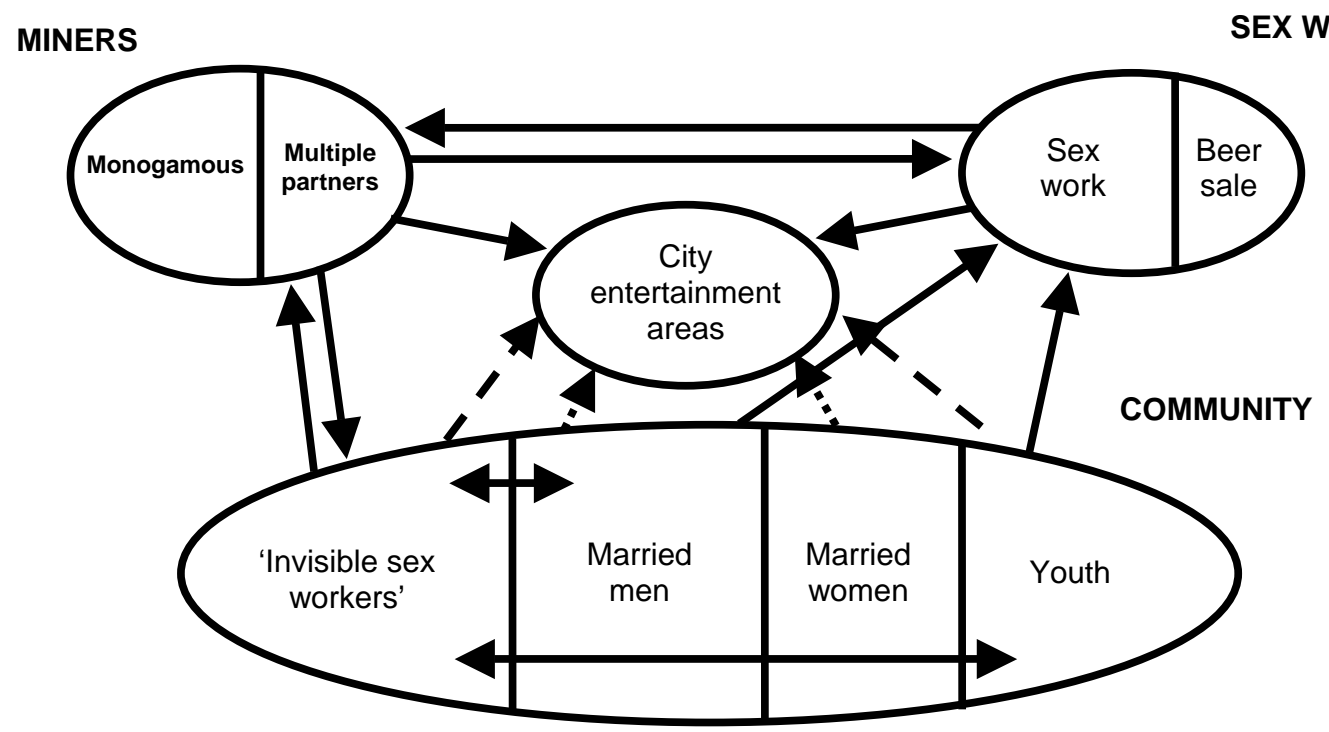

were from Carletonville, rising to 88 percent in 2001. When asked specifically about sex workers in the 2001 survey, only 9 percent of mine workers reported that they had ever had sex with a sex worker, demonstrating that it was only a small proportion of mine workers who had sex with SWs operating near the mine shafts. Unfortunately this question was not asked in the 1998 survey. Therefore, once data on STI/HIV prevalence and patterns of sexual networking were collected, it seemed unlikely that the interventions would have a significant impact on HIV prevalence. Strategies for increasing condom use and reducing the number of sexual partners should have been designed within the context of sexual parternerships existing among mine worker, SWs, and the broader Carletonville community.

Table 8 shows the casual sexual networks of respondents derived from quantitative data collected in the 2001 survey. The table shows that most male respondents tended to seek casual partners within their residential neighborhood. This was the same for women living in council and private housing (relatively wealthy neighborhoods). However, women from disenfranchised communities such as hotspots (referred to as squatter settlements) and site and service areas had more frequent relationships with mine workers. As expected, given that SWs were sampled from the hotspots around the mine compounds, the clients of these SWs came from mine hostels. It is interesting that mine workers had a relatively even spread of casual partners between squatter settlements, private housing, and council housing. The small percentage (1 percent) of mine workers who reported having a casual partner from the squatter settlements near mines, suggests that only a few mine workers had contact with self-identified SWs, while the majority had casual partners from other geographical locations and social strata (see Table 8). The fact that mine workers have a broad spectrum of casual partners affirms their economic power in the context of a society where rates of unemployment are very high.

Anecdotal evidence suggests that sex work occurs at squatter, site, and service settlements. Women living in these areas are not identified SWs but they operate as such. This group of women was originally overlooked in the intervention design. 
Table 8 Sexual networks for sex workers, mine workers, men, and women in the community in 2001 derived

\begin{tabular}{|c|c|c|c|c|c|c|c|c|c|}
\hline & $\begin{array}{l}\text { Council } \\
\%(n)\end{array}$ & $\begin{array}{l}\text { Private } \\
\%(n)\end{array}$ & $\begin{array}{c}\text { Squatter } \\
\text { settlement } \\
\%(n)\end{array}$ & $\begin{array}{l}\text { Site and } \\
\text { service } \\
\%(n)\end{array}$ & $\begin{array}{l}\text { Mine hostel } \\
\%(\mathrm{n})\end{array}$ & $\begin{array}{c}\text { Council } \\
\text { hostel } \\
\%(n)\end{array}$ & $\begin{array}{l}\text { Hotspotsl } \\
\text { squatter } \\
\text { settlements } \\
\text { near mines } \\
\%(n)\end{array}$ & $\begin{array}{c}\text { Don't know } \\
\%(n)\end{array}$ & $\begin{array}{l}\text { Total } \\
\%(n)\end{array}$ \\
\hline \multicolumn{10}{|l|}{ Men } \\
\hline Council & $60(29)$ & $23(11)$ & $15(7)$ & $2(1)$ & & & & & $100(48)$ \\
\hline Private & $20(8)$ & $65(26)$ & $5(2)$ & $8(3)$ & & & & $3(1)$ & $100(40)$ \\
\hline Squatter settlement & $23(14)$ & $10(6)$ & 64 (39) & $3(2)$ & & & & & $100(61)$ \\
\hline Site and service & $14(5)$ & $8(3)$ & $22(8)$ & $56(20)$ & & & & & $100(36)$ \\
\hline Total & $30(56)$ & $25(46)$ & $30(56)$ & $14(26)$ & & & & $1(1)$ & $100(185)$ \\
\hline \multicolumn{10}{|l|}{ Women } \\
\hline Council & $62(44)$ & $14(10)$ & $10(7)$ & & $13(9)$ & & & $1(1)$ & $100(71)$ \\
\hline Private & $37(15)$ & $51(21)$ & $5(2)$ & & $5(2)$ & & & $2(1)$ & $100(41)$ \\
\hline Squatter settlement & $10(13)$ & $3(4)$ & $31(39)$ & $4(5)$ & $49(61)$ & & & $2(2)$ & $100(124)$ \\
\hline Site and service & $20(12)$ & $10(6)$ & $15(9)$ & $31(19)$ & $25(15)$ & & & & $100(61)$ \\
\hline Total & $28(84)$ & $14(41)$ & $19(57)$ & $8(24)$ & $29(87)$ & & & $1(4)$ & $100(297)$ \\
\hline \multicolumn{10}{|l|}{ sWs } \\
\hline $\begin{array}{l}\text { Hotspots/squatter } \\
\text { settlements near } \\
\text { mines }\end{array}$ & $1(1)$ & $1(1)$ & & & $77(67)$ & $1(1)$ & $11(10)$ & & $100(87)$ \\
\hline \multicolumn{10}{|l|}{ Mine workers } \\
\hline Mine hostel & $28(61)$ & $20(44)$ & $37(80)$ & $7(16)$ & $1(3)$ & & $1(3)$ & $6(12)$ & 100 (219) \\
\hline
\end{tabular}




\section{Hgrizons}

The findings are pertinent for implementing an effective HIV/AIDS prevention strategy, and indicate the need for a clear understanding of the role of sexual networks in the community. The qualitative study in 2001 demonstrated the complexity of sexual relationships for people in Carletonville. Data collected on sexual networks indicated that women (including young women) had sexual relationships with mine workers, often for financial support. Respondents also felt that both men and women were engaged in sexual relationships with a variety of partners (often at the same time) for financial support and gifts. From FGDs with SWs and young people, three broad categories of partnerships or relationships could be differentiated: the spouse, the regular (steady) partner, and the casual partner. Respondents indicated that these types of partners were treated differently, with casual partners afforded the least amount of respect.

Analysis from the qualitative data found that the use of condoms depended on a number of factors. In particular, it was noted that women who are casual partners have little power to insist on condom use. Both male and female respondents argued that asking a regular partner to use a condom was seen as indicative of unfaithfulness and lack of trust. Alcohol use was also identified as a factor resulting in people not using condoms. Most respondents therefore felt that it was difficult to negotiate condom use in general and that it was more difficult for women, who lack power in both casual and regular relationships. SWs also were influenced by the amount of money paid for sex. A worker illustrated the dilemma between poverty and the level of acceptable risk:

"Maybe he takes out hundred rands, you will end up sacrificing life for it [by not using a condom]. You find that you haven't paid rent and then you go for that hundred rands, so that you pay your rent."

Information collected on sexual networks indicates that concurrent partnerships occur from a range of locations in Carletonville. Because the wider relationships in the informal settlements were not investigated and addressed, behavioral change interventions and the administration of PPT aimed solely at self-identified SWs at "hotspots" were not as effective as they could have been. The MIP made progress in identifying the "invisible SWs" living in the informal settlements, and many of these women participated in the PPT program. The lack of condom use by regular partners of SWs remains a major challenge in controlling the spread of STIs, including HIV/AIDS.

\section{The role of social organizations}

Membership in social organizations can be used to measure social connectedness of community members and the potential links with behavior and HIV risk. For the programs, this information was useful for designing community level HIV/AIDS prevention strategies. Quantitative data about membership in social organizations was collected both in the 1998 and 2001 surveys.

Forty percent of SWs considered themselves to be migrants, but a fairly high proportion were also members of social organizations in Carletonville. They belonged to church groups (just under 30 percent in both surveys) and stokvels (rotating credit schemes, 16 percent in 1998 and 13 percent in 2001); however, membership in burial societies decreased markedly from 26 percent in 1998 to 11 percent in 2001. The decline in membership could be explained through increased membership fees resulting from the rapidly increasing number of deaths occurring among this group. In-depth interviews and FGDs found that funeral costs tended to be high due 
to the need to return bodies for burial to other areas in South Africa or even to neighboring countries.

The mining industry was highly unionized and both surveys found high levels of trade union membership among mine workers (71 percent in 1998, increasing to 87 percent in 2001). Membership levels in other social groups were comparatively lower, although they did increase over time. Church membership increased substantially from 27 percent in 1998 to 42 percent in 2001, and membership in burial societies went up from 37 percent in 1998 to 47 percent in 2001. This may indicate that mine workers are planning more for the event of death, possibly as a result of the impact of HIV/AIDS. In addition, it may be because mine workers can better afford the membership fees. Membership in sports clubs increased slightly from 23 percent to 26 percent. Therefore, despite being migrants, many mine workers are members of work and non-work related social organizations that may also provide them with resources.

Interestingly, a smaller percentage of women in the community were members of social organizations in 2001 compared with 1998. The highest levels of group membership were found in church groups (61 percent and 53 percent), followed by burial societies (31 percent and 24 percent) and youth groups (15 percent and 16 percent). Membership in stokvels had dropped from 11 percent to 6 percent. Lack of financial resources could be a possible explanation, given that income levels declined over the three-year period.

Over the period of the intervention, a similar decline in membership in social organizations was noted among men in the community. Membership tended to be highest for church groups (50 percent and 48 percent) and sports groups (39 percent and 40 percent). Membership in burial societies dropped from 22 percent to 13 percent, trade unions from 18 percent to 6 percent, and stokvels from 10 percent to 3 percent. Similarly, the reported income of men in the community also fell between 1998 and 2001, which may explain why fewer men belonged to social organizations where membership fees or payments were required. Higher rates of unemployment in 2001 may have resulted in fewer trade union members.

Findings from both surveys indicated that membership in some social organizations may be associated with decreased HIV risk. Campbell (2002) analyzed data from the 1998 survey in Carletonville and found that group membership in certain organizations was associated with health-enhancing behaviors, such as fewer causal sexual partners and increased condom use with casual partners, and in some cases, with lower rates of HIV infection. For example, men belonging to a church were found to be less likely to have casual partners and, in the case of older men, less likely to drink alcohol. Young men who belonged to a sports club were less likely to be HIV positive. Young women belonging to youth and sports groups were less likely to be HIV positive or to have casual partners, and were more likely to use condoms with casual partners. However, the study found that young men and women who belonged to a stokvel were more likely to drink and be HIV positive. It is possible that some individuals identified with certain norms and activities of social organizations and thus self-selected to belong to certain groups.

Similarly, in the 2001 survey HIV prevalence rates were lower for respondents in the community who were youth or sports group members. When results were disaggregated by sex, HIV prevalence for women was lower for church group members. For men, HIV prevalence was higher for political party, trade union or burial society members. For mine workers, prevalence rates were higher for members of trade unions, burial societies, and sports groups, while prevalence was lower for church group members. Multivariate analysis found that lower 


\section{Hgrizons}

HIV prevalence levels were associated with membership in a youth group for men but with membership in church and youth groups for women.

Qualitative research was conducted to investigate how group membership shaped individual norms and values and the social context in which sexual behavior takes place. Eleven FGDs and 11 in-depth interviews were conducted with members of social organizations, including stokvels, burial societies, church groups, sports groups, women's groups, and political party organizations. Respondents were asked about their membership in organizations, the activities undertaken by organizations, and whether belonging to an organization affected their attitudes and behaviors. In addition, background information on the different types of social groups was collected.

Findings from the qualitative research identified some of the ways that group membership may influence individual behavior. For example, some organizations provided members with information and education and social support to develop skills to negotiate gender and sexual behavior norms. But competing factors neutralizing the positive effects of group membership include the promotion and consumption of alcohol, acceptance of multiple sexual partners, and 'macho' ideas about masculinity. Negative aspects were more easily identified in stokvels, political parties, and burial societies, while positive elements were found in sports groups, church organizations, and women's organizations.

Messages communicated in organizations were not always consistent, and their effect on sexual health seems both complex and contradictory for members. Many of the organizations presented both positive and negative messages. For example, church organizations were positive in terms of their promotion of ideas about monogamy and sobriety, yet some did not provide members with information about sexual health and the importance of condom use. Secondly, for individuals who belonged to more than one organization, it was not always clear which group membership exerted the most influence on individual attitudes and behavior.

Respondents recommended that the program should experiment with interventions to promote open discussion of sexuality in social organizations, train organization leaders to provide accurate information and advice regarding sexual health, create a positive climate in which members can negotiate safer and more positive sexual and gender norms, and establish peer education to address issues of stigma and discrimination. In addition, there is a need to test innovative ways to harness the positive aspects and to reduce the negative effects of group membership.

\section{Community mobilization and project management}

When the MIP began in 1998, it was managed through a loosely formed Stakeholders' Committee, which was made up of representatives from a local AIDS community organization in Carletonville, Central and Provincial Government, the private sector, research institutions, donors, and community members. At the end of 2001 the MIP faced an uncertain future when donor funding came to an end. This uncertainty gradually changed, as the community increasingly got involved in the management of the MIP. In 2001 a Board of Management was formed in order to formulate broad policies related to the project and to manage the staff of the MIP. The Board continues to operate and consists of participants from various sectors including local government, Carletonville AIDS organizations, mining houses, trade unions, and research and donor groups. The stakeholders on the Board provide a range of technical expertise to the community. 
Over the years, the MIP has built a groundbreaking alliance between the community and private sector. This broadening of program "ownership" has led to continuity and sustainability. Even though formal funding from donors ended in October 2001, SWs and other high-risk groups in the Carletonville area continue to receive key STI services, including PPT services from mobile clinics. The mining industry has assumed responsibility for the continuation of the PPT program to treat curable STIs among SWs. The peer education program continues among SWs, the mines have instituted an HIV program among mine workers, and STI case management is available through public, private, and mining clinics. In addition, the mining sector is able to provide management expertise and has begun to train members of the Board in project management. The mining sector has also aided in the procurement of supplies and the logistics of running the STI programs.

The current private-public partnerships of the project appear to be succeeding. The partnership has resulted in greater acceptability of the project by the community and capacity building in terms of general project management. SWs are key stakeholders in the project, but they are currently not represented on the management Board. A proposal to include sex worker representation is currently under discussion. 


\section{Hgrizons}

\section{Discussion}

The Mothusimpilo Intervention Project (MIP) began in 1998 and continues to date. The project interventions aimed to reduce STI prevalence and HIV incidence among SWs, mine workers, and the community of Carletonville. Unfortunately, these objectives were not met by the end of 2001. Nonetheless, the project provides valuable lessons in terms of the process of implementation of large-scale STI/HIV interventions.

Knowledge of risky sexual behavior and the increased risk of STI/HIV transmission improved during the project implementation, but behavior change did not occur. HIV prevalence increased among SWs, mine workers, and women in the community, with only a slight decrease (not significant) among men in the community. For other STIs, prevalence levels among mine workers generally decreased and remained basically unchanged among SWs. Among men in the community, the levels also remained constant, which is in contrast to the general upward trend for nearly all STIs for women.

Why did this happen? Baseline findings indicate that the prevalence of both STIs and HIV infection were high in all studied groups. HIV prevalence levels were highest among SWs followed by women in the community. Sixty-nine percent of SWs and 37 percent of women in the community were HIV positive in 1998. These figures are far higher than the antenatal HIV prevalence rate of 22.5 percent recorded for the province of Gauteng (where Carletonville is located) in the same year (DOH 2001). HIV prevalence was also comparatively high among mine workers (29 percent) and men in the community (22 percent), given that estimated HIV prevalence in the total population in Gauteng in 1998 was about 10 percent (SAHR 2002). These figures suggest that the HIV epidemic was generalized at the beginning of the project and that targeting SWs and mine workers was not sufficient to reduce levels of STIs and HIV in the general community.

The results from the Carletonville study must be considered in the context of other large-scale STI intervention studies in the region, which resulted in inconsistent outcomes with regard to HIV incidence. While the Mwanza study in Tanzania found that improved syndromic management of STIs reduced the incidence of HIV infection by 40 percent and that syndromic management was a cost-effective prevention strategy (Grosskurth et al. 2000), other interventions have not been successful. An intervention study in Rakai, Uganda, showed no effect on HIV incidence. Gray et al. (1999) argue that in Rakai, periodic presumptive treatment (PPT) of STIs was unlikely to substantially reduce HIV incidence, given the more advanced stage of the epidemic, the availability of STI treatment outside of the trial, and the prevalence of viral, incurable STIs in the population, which affect the outcome of STI programs. It was concluded that in a mature HIV epidemic, STI control is less likely to result in a reduction in HIV incidence at the general population level. However, the lack of evidence that STIs had an impact on HIV incidence in Carletonville, where HIV prevalence is high, should not distract programs from the importance of long term commitment to addressing STIs as a public health concern.

Although PPT was administered regularly to SWs, the potential for re-infection was high due to the fact that their regular and casual partners were not treated and condom use remained low. Survey data showed that in both 1998 and 2001, 41 percent of SWs did not use condoms consistently with clients and that condom use with regular partners was very low. Therefore, despite being treated for STIs, SWs were still likely to be re-infected by either their regular 
partners or their clients. It is also unclear what percentage of self-identified SWs participated in the PPT program and how regularly these participants returned for repeat treatment.

STI treatment services available to the various population groups in Carletonville included public health facilities, mine clinics, general practitioners, and traditional healers. Though mine workers had access to treatment at mine clinics, a significant number of them used private doctors and traditional healers, while SWs increasingly used the project's services provided by mobile clinics. Women and men in the community used public health services. A qualitative study in 2000 raised doubts about the adequacy of management of STIs by general practitioners who, in general, were not following the syndromic management approach. Even in public facilities where syndromic management was implemented extensively, management of STIs was unsatisfactory. Despite interventions to improve STI treatment and quality of services, not all respondents received appropriate care. This raised concerns given the context of widespread sexual networks with high levels of multiple partners and low use of condoms.

The intense peer education program for SWs did not bring about the expected behavior change. High levels of unemployment and limited job opportunities for women in Carletonville had resulted in many women turning to sex work as a source of income. Women in the community were found to be economically vulnerable, and despite their knowledge of HIV/AIDS, they did not change their sexual behavior. Qualitative data highlighted some of the difficulties faced by women in negotiating use of condoms in relationships. While men reported that it was difficult to use a condom with regular partners as it raised issues of trust, women found it difficult to negotiate condom use for different reasons: fear of abandonment, loss of economic support, and physical violence.

Some positive behavior changes were noted among mine workers, such as a drop in the proportion of workers reporting a casual partner in the 12 months prior to the study and significant increases in reported condom use with their last casual partner. However, in an environment where HIV prevalence was already high among SWs and in the community at large, the impact on HIV prevalence is likely to be limited. It is not clear whether a more comprehensive peer education program for mine workers would have resulted in greater changes in sexual behavior. A higher proportion of men in the community reported using condoms with their last casual partner, but this was in the context of a higher proportion who reported more casual partners 12 months prior to the survey.

Qualitative data on social organizations revealed some areas where interventions can be introduced to reduce risky sexual behavior. Respondents said that although they knew about HIV/AIDS, they continued to engage in risky behavior due to a variety of factors, including norms that accept and encourage multiple partners (especially among men), the commoditization of sex, resistance to condom use, and alcohol abuse. This points to the importance of involving men in more interventions. The MIP mainly focused on interventions for SWs, but qualitative and quantitative data revealed that SWs and women in the larger community did not have the power to insist on condom use. Focusing more on men who tend to have economic and social power may therefore yield better dividends in terms of behavior change.

The project also provided valuable lessons in terms of community mobilization, stakeholder participation in a large-scale project, and local capacity building to manage similar STI/HIV projects. Initially, the project set up an infrastructure that trained service providers in syndromic management to provide high-quality STI services, and this was extended to provide PPT services to SWs. Though the project was initially managed by a group of researchers, this 


\section{Hgrizons}

function was later transferred to a Board of Management that was elected by the community and that was composed of elected participants from various levels of government, Carletonville AIDS organizations, mining houses, trade unions, and research and donor groups. This broadening of program "ownership" and the development of private-public sector partnerships were critical for program sustainability. The partnership resulted in greater acceptability by the community and greater capacity building in general project management.

However, the process of project implementation has not been without challenges and this is amply discussed in Campbell's (2003) book on the MIP. In this book, she raises issues about difficulties of the original stakeholder group. The project suffered from a lack of commitment and no common vision about the purpose of the project, as well as weak coordination and a general mistrust among partners. Further, she argued that the project management team lacked the technical skills necessary to run such a large community project, including management expertise and conflict mediation skills.

With such a large number of stakeholders, these shortcomings were expected but the new Board of Management addressed a number of them. Meetings began to take place regularly in Khutsong Township rather than in Johannesburg, thus enabling greater community participation. The mining houses also assumed more responsibility, including financial responsibility for the PPT program for SWs. Despite limited donor funding, the project continues to run limited project interventions, mostly focused on ensuring PPT for SWs and peer education. While MIP started out as an internationally funded project, it has been transformed into a locally managed community project. The project has provided important information on the challenges of implementing interventions in high prevalence communities and on the obstacles facing multi-stakeholder management of projects. While many of the challenges facing the project still exist, the project seems to have achieved more local buy-in. 


\section{Recommendations}

This section discusses lessons and recommendations from the Mothusimpilo Intervention Project (MIP) as well as the implications of the findings for other workplace and community projects in similar contexts.

\section{Implementing contextually relevant and sustained peer education}

- The MIP should coordinate with other peer education programs to reach all target and key sub-populations groups that are part of the sexual networks. In a generalized epidemic, behavior change interventions should cover all the subgroups in order to reduce unsafe and risky behaviors.

- The program should test whether targeting men is a better strategy for encouraging condom use, given that men have more power in controlling the use of condoms with casual partners. Over three years, reported condom use improved among mine workers and males in the community, but women and SWs reported no change. Though encouraging, there is still a need to encourage men with STIs to use condoms with all their sexual partners, and for those who do not live with their regular partners to use condoms with both regular and casual partners consistently. The lack of change in condom use among females suggests the need for preventive strategies specifically for them, namely, the female condom.

- In general, programs that use peer education as a behavior change strategy need to provide adequate training and support for peer educators. Peer education was found to be difficult to implement in settings where didactic learning is favored. Innovative responses to ensure stakeholder buy-in and participation also need to be developed (for example, integrating life skills programs into the school curriculum).

\section{STI treatment}

- Careful expansion of interventions, especially PPT, to include regular partners of SWs and high-risk women in the community, should be considered in order to have an impact on STI prevalence and HIV incidence. Regular partners who were not part of the program were suspected to be a source of infection and re-infection among SWs who had enrolled in the PPT program. An initial analysis of the pattern of infections of STIs and sexual networks in the community is critical before interventions are introduced.

- The vulnerability of women in the general Carletonville community was clearly demonstrated in this project, and special creative initiatives need to be developed to address the risk of this group. With respect to levels of HIV and other STIs, community women ranked second after SWs. The behavior of their partners is a leading cause of the high rates of infection. Both men and women had multiple partners and did not use condoms with their regular partners. For women, this aggravated their vulnerability because they were unable to insist on condom use. 


\section{Hgrizons}

- Targeting groups where STI prevalence levels are still relatively low, for example, youth and possibly newly recruited mine workers, may be an effective strategy in the future. At the time of recruitment, a good prevention program for mine workers may help stem new infections in this group. The steep rise of HIV prevalence after the teenage years suggests that strong and sustained interventions for young people in and out of school could prevent many infections.

- Attention to the quality of STI services should continue to be a key theme of the MIP. Even when services are accessible, clients may not use them due to concerns about the quality of care provided, privacy, and stigma.

- In addition to HIV prevention programs in Carletonville, there are programs that deliver treatment, care, and support services. These programs need to be coordinated and integrated with broader prevention programs.

\section{The role of social organizations}

- A large proportion of the community belongs to social organizations, so there is a need for more experimentation with interventions aimed at social or community organizations. Interventions could include training organization leaders in providing accurate information and advice to create a positive climate in which members can mediate gender norms and receive information. Leadership training on issues around HIV/AIDS can help leaders of social organizations to establish a positive climate in which group members can negotiate sexual and gender norms, and to implement a peer education program to address issues of stigma and discrimination.

- Programs should develop innovative ways to harness the positive aspects and reduce the negative effects of group membership in social organizations.

\section{Stakeholder participation and community mobilization}

- MIP has cultivated good partner relationships between the community and the private sector, and this relationship should be encouraged, as it is crucial for greater acceptance of the project and its long-term sustainability. The mines are providing technical and project management support to the community project.

- The transformation process from a research project to a broad community-based project provides useful lessons (for example, in engaging the community, forming the Board of Management) for other large-scale intervention projects. A consultative process with the community, with a transparent governance process resulting from the election of a Board of Management, has led to acceptability and sustainability. 


\section{References}

Aral, S.O. 1999. "Sexual network patterns as determinants of STD rates: Paradigm shift in the behavioral epidemiology of STDs made visible," Sexually Transmitted Diseases (26)5: 262264.

Aral, S.O. et al. 1999. "Sexual mixing patterns in the spread of Gonococcal and Chlamydial infections," American Journal of Public Health 89(6): 825-833.

Ballard, R. 1996. "STDs on the mines: the nature of the problem," in B.G. Williams and C.M. Campbell (eds.), HIV/AIDS Management in South Africa: Priorities for the Mining Industry. Epidemiology Research Unit: Johannesburg, pp 111-114.

Boily, M., R. Poulin, and B. Masse. 2000. "Some methodological issues in the study of sexual networks: From model to data to model,” Sexually Transmitted Diseases 27(10): 558-71.

Boyles, S. 1995. “STD treatment reduces HIV in rural Tanzania,” AIDS Weekly 12(2).

Buve, A. et al. 2001. "Multicentre study on factors determining differences in rate of spread of HIV in sub-Saharan Africa: Methods and prevalence of HIV infection.” AIDS 15 (suppl 4): S15-S30.

Campbell, C. 2003. "Letting Them Die"-Why HIV/AIDS Intervention Programmes Fail. The International African Institute in association with James Currey (Oxford)/Indiana University Press (Bloomington)/Double Storey Books (a Juta Company, Cape Town).

Campbell, C. and C. MacPhail. 2002. "Peer education, gender and the development of critical consciousness: participatory HIV prevention by South African youth," Social Science and Medicine 55(2): 331-45.

Campbell, C. and Y. Mzaduime. 2002. "How can HIV be prevented in South Africa? A social perspective,” British Medical Journal 324(26): 229-232.

Campbell, C., B. Williams, and D. Gilgen. 2002. "Is social capital a useful conceptual tool for exploring community level influences on HIV infection? An exploratory case study from South Africa,” AIDS Care 14(1): 41-54.

Campbell, C. and B. Williams. 1999. "Beyond the biomedical and behavioural: towards an integrated approach to HIV prevention in the Southern African mining industry.” Social Science \& Medicine 48(11): 1625-1639.

Department of Health. 2001. "National HIV and Syphilis Sero-prevalence Survey 2000.” Pretoria: Department of Health. available at http://196.36.153.56/doh/aids/index.html.

Gray, R.H. et al. 1999. "Relative risks and population attributable fraction of incident HIV associated with symptoms of sexually transmitted diseases in Rakai District, Uganda.” AIDS 13(15): 2113-2123. 


\section{Hgrizons}

Gilgen, D. et al. 2000. The Natural History of HIV/AIDS in South Africa: A Biomedical and Social Survey in Carletonville. CSIR: Johannesburg.

Grosskurth, H. et al. 2000. "Control of sexually transmitted diseases for HIV-1 prevention: understanding the implications of the Mwanza and Rakai trials,” The Lancet 355(9219): 19811987.

Harrison, A. and N. Ntuli. 1999. "Assessment of services for sexually transmitted diseases in the public and private sectors: Perspectives of service users and providers.” Unpublished report submitted to Horizons.

Ijumba, Petrida, Antoinette Ntuli, and Peter Barron. (eds.) 2002. South African Health Review. 2002. Durban, South Africa: Health Systems Trust.

International Organization for Migration and UNAIDS. "Mobile populations and HIV/AIDS in the Southern African region: Desk review and bibliography on HIV/AIDS and mobile populations," IOM-UNAIDS Reports on Mobile Populations and HIV/AIDS Series 1.

Lamptey, P.R.. 2002. "Reducing heterosexual transmission of HIV in poor countries," British Medical Journal 324: 207-211.

Lagarde, E. 2000. "Assessing the impact of concurrent partnerships on the HIV epidemic: Indicator definitions and application to survey data from five urban communities of subSaharan Africa.” Paper presented at IUSSP Conference on Partnership Networks, Chiang Mai, Thailand, 7-10 February 2000.

Morris, M. 1997. “Sexual networks and HIV,” AIDS 11 (Supp A): S209-S216.

Morris, M. and M. Kretzchmar. 1997. "Concurrent partnerships and the spread of HIV,” AIDS 11: 641-648

Nelson Mandela/HSRC. 2003. "Nelson Mandela/HSRC study of HIV/AIDS: South Africa national HIV prevalence, behavioral risks and mass media: household survey, 2002.” HSRC: Cape Town.

Schwarcz, S. 1999. “A new HIV test to detect recent infections.” FOCUS 14(3): 5-6.

Sexually Transmitted Infection Reference Centre of the National Institute for Communicable Diseases. 2001. “Carletonville project, surveillance report, January-December 2001.”

Van Campenhout, L. et al. (eds). 1997. Sexual Interaction and HIV Risk: New Conceptual Perspectives in European Research. London: Taylor and Francis.

Williams B. and C. Campbell. 1999. "Community mobilization as an HIV prevention strategy: challenges and obstacles (South Africa),” Sexual Health Exchange 2: 4-6. 


\section{Hgrizons}

Horizons is a global operations research program designed to:

- Identify and test strategies to improve HIV/AIDS prevention, treatment, and care programs and services.

- Disseminate best practices and promote research utilization with a view toward scaling up successful interventions.

\section{(2) Population Council}

Horizons is implemented by the Population Council in collaboration with

- International Center for Research on Women (ICRW)

- International HIV/AIDS Alliance

- Program for Appropriate Technology in Health (PATH)

- Tulane University

- Family Health International (FHI)

- Johns Hopkins University

For more information, please contact:

Horizons Program, Communications Unit 4301 Connecticut Avenue, NW Suite 280 Washington, DC 20008 USA

Tel: 202-237-9400

Fax: 202-237-8410

Email:horizons@pcdc.org www.popcouncil.org/horizons 